\title{
Diacetate Naphthoquinone Derivatives Tethered to 1,2,3-Triazoles: Synthesis and Cytotoxicity Evaluation in Caco-2 Cells
}

\author{
Dora C. S. Costa, ${ }^{\circledR a}$ Adriane S. Francisco, ${ }^{b}$ Beatriz V. A. Matuck, ${ }^{\circledR a}$ Priscila S. Furtado, ${ }^{\circledR c}$ \\ Alana A. S. C. de Oliveira, ${ }^{c}$ Vitor W.-H. Rabelo, ${ }^{\circledR}$ Plínio C. Sathler, ${ }^{\circledR c}$ Paula A. Abreu, ${ }^{\circ d}$ \\ Vitor F. Ferreira, ${ }^{\oplus e}$ Luiz Cláudio R. P. da Silva ${ }^{\circledR b}$ and Fernando C. da Silva ${ }^{\oplus *, a}$ \\ ${ }^{a}$ Departamento de Química Orgânica, Instituto de Química, Universidade Federal Fluminense, \\ Campus do Valonguinho, 24020-150 Niterói-RJ, Brazil \\ ${ }^{b}$ Grupo de Nanoteranósticos (GNT), Faculdade de Farmácia, \\ Universidade Federal do Rio de Janeiro, 21941-902 Rio de Janeiro-RJ, Brazil \\ 'LABHEx, Faculdade de Farmácia, Universidade Federal do Rio de Janeiro, \\ 21941-902 Rio de Janeiro-RJ, Brazil \\ ${ }^{d}$ Laboratório de Modelagem Molecular e Pesquisa em Ciências Farmacêuticas (LaMCiFar), \\ NUPEM, Universidade Federal do Rio de Janeiro, Campus Macaé, 27965-045 Macaé-RJ, Brazil \\ ${ }^{e}$ Departamento de Tecnologia Farmacêutica, Faculdade de Farmácia, \\ Universidade Federal Fluminense, 24241-002 Niterói-RJ, Brazil
}

\begin{abstract}
Acetylated compounds prepared from naphthoquinones have been reported as antitumoral prodrugs. Exploring the synthetic versatility of the naphthoquinone and triazolic nuclei, herein we report a simple and efficient synthetic route to prepare a series of sixteen prodrugs prototype of 1,2,3-triazoles-naphthoquinodoic acetyl derivatives. The compounds 10a-10h and 11a-11h were obtained by oxidative cycloaddition reaction between lawsone and 4-vinyl-1 $\mathrm{H}$-1,2,3-triazoles promoted by ceric ammonium nitrate $(\mathrm{CAN})$ in alkaline medium followed by reductive acetylation of the quinones in excess of metallic zinc and acetic anhydride in yields up to $>98 \%$. All derivatives revealed to be hemocompatible and the compound 11e exhibited the most promising profile against Caco-2 cells showing the higher selectivity index. Molecular docking suggests that these compounds could exert their cytotoxic activity through inhibition of one topoisomerase II isoform, at least.
\end{abstract}

Keywords: naphthoquinones, lapachones, cancer, human epithelial colorectal adenocarcinoma cells, molecular docking, topoisomerase

\section{Introduction}

Cancer is a strong threat to the life of the human being, according to data from the World Health Organization, this represents the second largest cause of death in the world, having been responsible for about 9.6 million deaths in 2018. ${ }^{1}$ Worldwide, for every six deaths, one is due to cancer, and $70 \%$ of these deaths occur in countries with weaker economies.

In the last years, many successfully specific anticancer agents have been reported, however, the research for non-specific anticancer drugs remaining very important,

*e-mail: luizclaudio@pharma.ufrj.br; fcsilva@id.uff.br

Editor handled this article: Teodoro S. Kaufman especially for the patients that have developed resistance or not respond to the cancer-specific agents. ${ }^{2}$ Deoxyribonucleic acid (DNA) topoisomerases have been shown to be interesting therapeutic targets for antibacterial and anticancer treatments. In this sense, several promising classes of DNA topoisomerase inhibitors have been reported, such as, quinolones, ${ }^{3}$ indolinones, ${ }^{4}$ pyrimidines, ${ }^{5}$ indoles,${ }^{6}$ indazoles, ${ }^{7}$ rhodanines, ${ }^{8}$ pyrazolothiazoles, ${ }^{9}$ pyrrolopyrimidines, ${ }^{10}$ pyrrolamides ${ }^{11}$ and naphthoquinones. ${ }^{12-14}$

Naphthoquinones are natural and synthetic substances known for their biological diversity. In fact, several studies ${ }^{15-19}$ show that they have a high potential for pharmacological activities, and some of them have become drugs or served as prototypes for the development of promising new molecules with antitumor action. 
$\beta$-Lapachone is a natural naphthoquinone and its ARQ761 formulation, for example, is currently in phase 2 of clinical trials as an adjuvant in the treatment of pancreatic cancer (works as an NQO1, NAD(P)H quinone dehydrogenase 1, inhibitor) and in phase $1 \mathrm{~b}$ for the treatment of several solid tumors. ARQ761 is administered intravenously, being converted to $\beta$-lapachone (1) in vivo. ${ }^{20}$

However, naphthoquinones are cytotoxic and lead cells to a programmed death (apoptosis) through their oxidative mechanism, which is often attenuated in nanoformulations or associations as in studies that aim to minimize the cardiotoxicity of doxorubicin, for example. ${ }^{21}$ On the other hand, the strategy of using acetylated naphthoquinone derivatives appears to be very promising.

Ma et al. ${ }^{22}$ reported the preclinical evaluation of $\beta$-lapachone derivative nanotherapeutics ( 2 and $\mathbf{3}$ ) for the treatment of non-small cell lung cancer (NSCLC) that overexpress NAD(P)H: quinone oxidoreductase 1 (NQO1) in efficiencies $>95 \%$ with significantly reduced hemolysis and methemoglobinemia that currently limits ARQ761 formulations (Figure 1). Moreover, Reichstein et al..$^{23}$ noted that the acetylated derivatives $\mathbf{4}$ and $\mathbf{5}$ were more efficient than their carbonylated precursors suppressing keratinocyte hyperproliferation in the low micromolar range (Figure 1).

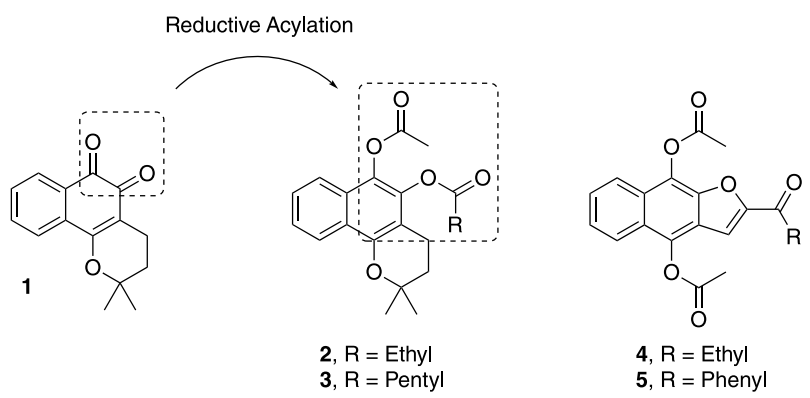

Figure 1. Some antitumoral naphthoquinones derivatives.

In our previous work, ${ }^{24}$ we described a series of naphthoquinone-1H-1,2,3-triazole hybrids (8a-8h and 9a-9h) and evaluated them for in vitro cytotoxic activity against human tumor cell lines (MDA-MB231, Calu-3 and Caco-2) and healthy cells (Vero). Compound 9a exhibited the most promising profile due to its selective cytotoxic action against colon adenocarcinoma cells (Caco-2). Following our study, herein, we presented the synthesis and in vitro evaluation of a series of eight 2-(1-phenyl1H-1,2,3-triazol-4-yl)-2,3-dihydronaphtho[2,3-b]furan4,9-diyl diacetate (10a-10h) and eight 2-(1-phenyl$1 H$-1,2,3-triazol-4-yl)-2,3-dihydronaphtho[1,2-b]furan4,5-diyl diacetate (11a-11h), prepared from of $\mathbf{8 a - 8 h}$ and 9a-9h, against Caco- 2 cells and also evaluated their cell viability on Vero cells.

\section{Experimental}

\section{Chemistry}

Materials and methods

The reagents were purchased from Sigma-Aldrich (São Paulo, Brazil) and were used without further purification. The compounds $\mathbf{8 a - 8 h}$ and $\mathbf{9 a - 9 h}$ was prepared as we previously reported. ${ }^{24}$ Column chromatography was performed with silica gel 60 (Merck 70-230 mesh, São Paulo, Brazil). Analytical thin layer chromatography was performed with silica gel plates (Merck, São Paulo, Brazil, TLC silica gel $60 \mathrm{~F}_{254}$ ), and the plates were visualized using UV light (SigmaAldrich, São Paulo, Brazil). The indicated yields refer to homogeneous materials purified by chromatography and confirmed by spectroscopic techniques. Melting points were obtained on a Thermo Scientific 9100 apparatus (Waltham, USA) and were uncorrected. Infrared spectra were collected on a Varian (Sigma-Aldrich, São Paulo, Brazil) model 660 FT-IR spectrophotometer, and the spectra were calibrated relative to the $1601.8 \mathrm{~cm}^{-1}$ absorbance of polystyrene. ${ }^{1} \mathrm{H}$ and ${ }^{13} \mathrm{C}$ nuclear magnetic resonance (NMR) were recorded at room temperature using a Varian Mercury 300 (Palo Alto, USA) or Varian Mercury $500 \mathrm{MHz}$ (Palo Alto, USA), in the $\mathrm{CDCl}_{3}$. The chemical shift data were reported in units of $\delta$ (ppm) downfield from solvent, and the solvent was used as an internal standard; coupling constants $(J)$ are reported in hertz and refer to apparent peak multiplicities. Highresolution mass spectra (HRMS) were recorded on a WATERS MICROMASS Q-TOF mass spectrometer (Milford, USA).

\section{General procedure for the preparation of $10 \mathrm{a}-10 \mathrm{~h}$ and 11a-11h}

To a suspension of naphthoquinone $(\mathbf{8 a - 8 h}$ or $\mathbf{9 a -}$ $\mathbf{9 h}, 40 \mathrm{mg})$ in acetic anhydride $(4 \mathrm{~mL})$ a few drops of pyridine were added. After that, $700 \mathrm{mg}$ of activated $\mathrm{Zn}^{0}$ were added and the mixture was kept under stirring at room temperature (rt) for 5 days. Then, the mixture was diluted with distilled water, extracted with ethyl acetate $(3 \times 50 \mathrm{~mL})$ and the organic layer washed with distilled water $(3 \times 50 \mathrm{~mL})$. The combined organic layers were dried over with anhydrous sodium sulphate, filtered off and concentrated under vacuum. The resulting residue was purified by silica gel chromatography, using an ethyl acetate/hexane mixture (1:3) as eluent in isocratic mode. The compounds 10a-10h and 11a-11h were obtained as white solids in very good yields. 
2-(1-Phenyl-1H-1,2,3-triazol-4-yl)-2,3-dihydronaphtho [2,3-b]furan-4,9-diyl diacetate (10a)

White solid, 74\% (35.0 mg) yield; mp 191-192 ${ }^{\circ} \mathrm{C}$; IR attenuated total reflectance (ATR) $v / \mathrm{cm}^{-1} 1753,1660$, 1444, 1362, 1200, 1169, 1154, 1026, 1003, 973, 761, 689, 573; ${ }^{1} \mathrm{H} \mathrm{NMR}\left(500.00 \mathrm{MHz}, \mathrm{CDCl}_{3}\right) \delta 2.44(\mathrm{~s}, 3 \mathrm{H}), 2.48(\mathrm{~s}$, $3 \mathrm{H}), 3.53(\mathrm{dd}, J 16.1$ and $4.3 \mathrm{~Hz}, 1 \mathrm{H}), 3.82(\mathrm{dd}, J 16.1$ and $8.9 \mathrm{~Hz}, 1 \mathrm{H}), 6.23-6.28(\mathrm{~m}, 1 \mathrm{H}), 7.37-7.41(\mathrm{~m}, 2 \mathrm{H}), 7.46-$ $7.51(\mathrm{~m}, 3 \mathrm{H}), 7.76-7.80(\mathrm{~m}, 2 \mathrm{H}), 7.70-7.74(\mathrm{~m}, 2 \mathrm{H}), 8.18$ $(\mathrm{d}, J 0.6 \mathrm{~Hz}, 1 \mathrm{H}) ;{ }^{13} \mathrm{C}$ NMR (attached proton test (APT), $75.0 \mathrm{MHz}, \mathrm{CDCl}_{3}$ ) $\delta 20.9,35.6,79.4,120.2,120.4,120.7$, $121.1,121.4,123.9,124.6,125.2,127.2,128.8,128.9$, 129.9, 137.1, 140.4, 147.9, 149.3, 168.2, 168.8; HRMS (ESI) $m / z$, calcd. for $\mathrm{C}_{24} \mathrm{H}_{19} \mathrm{~N}_{3} \mathrm{NaO}_{5}[\mathrm{M}+\mathrm{Na}]^{+}: 452.12169$, found: $452.120466, \Delta 2.7 \mathrm{ppm}$.

2-(1-(p-Tolyl)-1H-1,2,3-triazol-4-yl)-2,3-dihydronaphtho[2,3-b]furan-4,9-diyl diacetate (10b)

White solid, 84\% (40.8 mg) yield; mp 198-199 ${ }^{\circ} \mathrm{C}$; IR (ATR) $v / \mathrm{cm}^{-1} 1748,1522,1446,1363,1227,1209,1172$, 1029, 995, 807, 732, 595; ${ }^{1} \mathrm{H}$ NMR $\left(500.00 \mathrm{MHz}, \mathrm{CDCl}_{3}\right)$ $\delta 2.38(\mathrm{~s}, 3 \mathrm{H}), 2.44(\mathrm{~s}, 3 \mathrm{H}), 2.47(\mathrm{~s}, 3 \mathrm{H}), 3.53(\mathrm{dd}, J 16.1$ and $4.5 \mathrm{~Hz}, 1 \mathrm{H}), 3.81(\mathrm{dd}, J 16.1$ and $9.1 \mathrm{~Hz}, 1 \mathrm{H}), 6.25$ (dd, $J 9.1$ and $4.5 \mathrm{~Hz}, 1 \mathrm{H}), 7.26(\mathrm{~d}, J 8.3 \mathrm{~Hz}, 2 \mathrm{H}), 7.37-$ $7.40(\mathrm{~m}, 1 \mathrm{H}), 7.47-7.50(\mathrm{~m}, 1 \mathrm{H}), 7.58(\mathrm{~d}, J 8.3 \mathrm{~Hz}, 2 \mathrm{H})$, 7.70-7.80 (m, 2H), $8.05(\mathrm{~d}, J 0.5 \mathrm{~Hz}, 1 \mathrm{H}) ;{ }^{13} \mathrm{C}$ NMR (APT, $\left.75.0 \mathrm{MHz}, \mathrm{CDCl}_{3}\right) \delta 20.7,21.1,35.4,79.2,120.0,120.2$, $120.4,121.0,121.2,123.7,124.4,124.9,127.0,128.8$, 130.2, 134.7, 138.8, 140.2, 147.8, 149.0, 168.0, 168.5; HRMS (ESI) $m / z$, calcd. for $\mathrm{C}_{25} \mathrm{H}_{21} \mathrm{~N}_{3} \mathrm{NaO}_{5}[\mathrm{M}+\mathrm{Na}]^{+}$: 466.13734, found: 466.136963, $\Delta 0.8 \mathrm{ppm}$.

2-(1-(4-Methoxyphenyl)-1H-1,2,3-triazol-4-yl)-2,3-dihydronaphtho[2,3-b]furan-4,9-diyl diacetate (10c)

White solid, 53\% (26.7 mg) yield; mp 190-192 ${ }^{\circ} \mathrm{C}$; IR (ATR) $v / \mathrm{cm}^{-1} 1750,1520,1435,1363,1519,1257,1212$, 1170, 1029, 993, 824, 759, 729, 573; ${ }^{1} \mathrm{H}$ NMR $(500.0 \mathrm{MHz}$, $\left.\mathrm{CDCl}_{3}\right) \delta 2.44(\mathrm{~s}, 3 \mathrm{H}), 2.47$ (s, 3H), 3.53 (dd, $J 16.1$ and $4.5 \mathrm{~Hz}, 1 \mathrm{H}), 3.78-3.81(\mathrm{~m}, 1 \mathrm{H}), 3.83(\mathrm{~s}, 3 \mathrm{H}), 6.23-6.26(\mathrm{~m}$, $1 \mathrm{H}), 6.97(\mathrm{~d}, J 9.1,2 \mathrm{H}), 7.37-7.40(\mathrm{~m}, 1 \mathrm{H}), 7.47-7.50(\mathrm{~m}$, 1H), $7.61(\mathrm{~d}, J 9.1 \mathrm{~Hz}, 2 \mathrm{H}), 7.70-7.79(\mathrm{~m}, 2 \mathrm{H}), 8.08(\mathrm{~d}$, $J 0.4 \mathrm{~Hz}, 1 \mathrm{H}$ ); ${ }^{13} \mathrm{C}$ NMR (APT, 75.0 MHz, $\mathrm{CDCl}_{3}$ ) $\delta 20.9$, 35.6, 55.8, 79.4, 114.9, 120.3, 120.4, 121.2, 121.4, 122.3, 123.9, 124.6, 125.1, 127.2, 128.9, 130.6, 140.4, 148.0, 149.1, 160.0, 168.2, 168.7; HRMS (ESI) $\mathrm{m} / \mathrm{z}$, calcd. for $\mathrm{C}_{25} \mathrm{H}_{21} \mathrm{~N}_{3} \mathrm{NaO}_{6}[\mathrm{M}+\mathrm{Na}]^{+}:$482.13226, found: 482.133129, $\triangle 1.8 \mathrm{ppm}$.

2-(1-(4-Acetamidophenyl)-1H-1,2,3-triazol-4-yl)-2,3-dihydronaphtho[2,3-b]furan-4,9-diyl diacetate (10d)

White solid, $88 \%$ (47.1 mg) yield; $\mathrm{mp} 240-241{ }^{\circ} \mathrm{C}$; IR
(ATR) $v / \mathrm{cm}^{-1} 1760,1737,1665,1522,1443,1365,1233$, 1214, 1175, 1032, 835; ${ }^{1} \mathrm{H}$ NMR (500.00 MHz, $\mathrm{CDCl}_{3}$ ) $\delta 2.16(\mathrm{~s}, 3 \mathrm{H}), 2.44(\mathrm{~s}, 3 \mathrm{H}), 2.47(\mathrm{~s}, 3 \mathrm{H}), 3.53(\mathrm{dd}, J 16.1$ and $4.1 \mathrm{~Hz}, 1 \mathrm{H}), 3.80(\mathrm{dd}, J 16.1$ and $9.0 \mathrm{~Hz}, 1 \mathrm{H}), 6.23(\mathrm{dd}, J 9.0$ and $4.1 \mathrm{~Hz}, 1 \mathrm{H}), 7.37(\mathrm{t}, J 7.6 \mathrm{~Hz}, 2 \mathrm{H}), 7.42(\mathrm{bs}, 1 \mathrm{H}), 7.47(\mathrm{t}$, $J 7.6 \mathrm{~Hz}, 2 \mathrm{H}), 7.62(\mathrm{~d}, J 6.6 \mathrm{~Hz}, 4 \mathrm{H}), 7.77-7.79(\mathrm{~m}, 2 \mathrm{H}), 8.10$ (bs, 1H); ${ }^{13} \mathrm{C}$ NMR (APT, 75.0 MHz, $\mathrm{CDCl}_{3}$ ) $\delta 20.7,24.6$, 35.3, 79.2, 119.9, 120.2, 120.4, 120.9, 121.2, 123.7, 124.4, 125.0, 127.0, 128.7, 132.8, 138.4, 140.2, 147.8, 149.0, 168.0, 168.3, 168.6; HRMS (ESI) $m / z$, calcd. for $\mathrm{C}_{26} \mathrm{H}_{22} \mathrm{~N}_{4} \mathrm{NaO}_{6}[\mathrm{M}$ $+\mathrm{Na}^{+}$: 509.14316, found: 509.145633, $\Delta 4.9 \mathrm{ppm}$.

2-(1-(4-Fluorophenyl)-1H-1,2,3-triazol-4-yl)-2,3-dihydronaphtho[2,3-b]furan-4,9-diyl diacetate (10e)

White solid, $44 \%(21.8 \mathrm{mg})$ yield; $\mathrm{mp} 182-184^{\circ} \mathrm{C}$; IR (ATR) v / $\mathrm{cm}^{-1} 1759,1518,1445,1434,1366,1253$, 1229, 1208, 1175, 1048, 1030, 835, 760, 730; ${ }^{1} \mathrm{H}$ NMR $\left(500.00 \mathrm{MHz}, \mathrm{CDCl}_{3}\right) \delta 2.44(\mathrm{~s}, 3 \mathrm{H}), 2.48(\mathrm{~s}, 3 \mathrm{H}), 3.51(\mathrm{dd}$, $J 16.1$ and $4.1 \mathrm{~Hz}, 1 \mathrm{H}), 3.82(\mathrm{dd}, J 16.1$ and $9.1 \mathrm{~Hz}, 1 \mathrm{H})$, $6.25(\mathrm{dd}, J 9.1$ and $4.1 \mathrm{~Hz}, 1 \mathrm{H}), 7.15-7.18(\mathrm{~m}, 2 \mathrm{H}), 7.37-$ $7.41(\mathrm{~m}, 1 \mathrm{H}), 7.48-7.51(\mathrm{~m}, 1 \mathrm{H}), 7.68-7.70(\mathrm{~m}, 2 \mathrm{H}), 7.79$ $(\mathrm{t}, J 7.5 \mathrm{~Hz}, 2 \mathrm{H}), 8.14$ (bs, $1 \mathrm{H}) ;{ }^{13} \mathrm{C}$ NMR (APT, $75.0 \mathrm{MHz}$, $\left.\mathrm{CDCl}_{3}\right) \delta 20.6,20.7,35.4,79.2,116.6(\mathrm{~d}, J 23.2 \mathrm{~Hz}), 120.1$, $120.2,120.8,121.2,122.4(\mathrm{~d}, J 8.6 \mathrm{~Hz}), 123.8,124.5,125.0$, 127.0, 128.7, 133.2 (d, J3.1 Hz), 140.3, 147.7, 149.4, 162.4 (d, $J 248.9 \mathrm{~Hz}$ ), 168.0, 168.6; HRMS (ESI) $\mathrm{m} / z$, calcd. for $\mathrm{C}_{24} \mathrm{H}_{18} \mathrm{FN}_{3} \mathrm{NaO}_{5}[\mathrm{M}+\mathrm{Na}]^{+}: 470.11227$, found: 470.110080, $\triangle 4.7 \mathrm{ppm}$.

2-(1-(4-Chlorophenyl)-1H-1,2,3-triazol-4-yl)-2,3-dihydronaphtho[2,3-b]furan-4,9-diyl diacetate (10f)

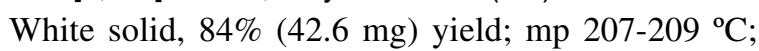
IR (ATR) v / $\mathrm{cm}^{-1} 1740,1502,1444,1434,1362,1253$, 1229, 1202, 1171, 1092, 1025, 992, 964, 899, 756, 729, 573; ${ }^{1} \mathrm{H}$ NMR $\left(500.00 \mathrm{MHz}, \mathrm{CDCl}_{3}\right) \delta 2.44(\mathrm{~s}, 3 \mathrm{H}), 2.48$ (s, 3H), $3.50(\mathrm{dd}, J 16.1$ and $4.0 \mathrm{~Hz}, 1 \mathrm{H}), 3.82$ (dd, $J 16.1$ and $8.9 \mathrm{~Hz}, 1 \mathrm{H}), 6.25(\mathrm{dd}, J 8.9$ and $3.9 \mathrm{~Hz}, 1 \mathrm{H}), 7.38(\mathrm{~m}$, 1H) $7.44(\mathrm{~d}, J 9.0 \mathrm{~Hz}, 2 \mathrm{H}), 7.48-7.51(\mathrm{~m}, 1 \mathrm{H}), 7.67(\mathrm{~d}$, $J 9.0 \mathrm{~Hz}, 2 \mathrm{H}), 7.79(\mathrm{t}, J 8.2 \mathrm{~Hz}, 2 \mathrm{H}), 8.18(\mathrm{~d}, J 0.5 \mathrm{~Hz}, 1 \mathrm{H})$; ${ }^{13} \mathrm{C} \mathrm{NMR}$ (APT, $126.00 \mathrm{MHz}, \mathrm{CDCl}_{3}$ ) $\delta$ 20.62, 20.65, 35.42, 79.09, 119.91, 120.16, 120.78, 121.15, 121.53, 123.76, 124.46, 124.97, 127.02, 128.71, 129.82, 134.41, 135.40, 140.27, 147.69, 149.47, 167.97, 168.60; HRMS (ESI) $\mathrm{m} / \mathrm{z}$, calcd. for $\mathrm{C}_{24} \mathrm{H}_{18} \mathrm{ClN}_{3} \mathrm{NaO}_{5}[\mathrm{M}+\mathrm{Na}]^{+}$: 486.08272, found: 486.082617, $\Delta 0.2 \mathrm{ppm}$.

2-(1-(3,4-Dichlorophenyl)-1H-1,2,3-triazol-4-yl)-2,3-dihydronaphtho[2,3-b]furan-4,9-diyl diacetate (10g)

White solid, 93\% (46.4 mg) yield; mp 224-225 ${ }^{\circ} \mathrm{C}$; IR (ATR) $v / \mathrm{cm}^{-1} 1746,1493,1364,1211,1172,1049$, 1029, 994, 762, 732, 573; ${ }^{1} \mathrm{H}$ NMR (300.00 MHz, $\mathrm{CDCl}_{3}$ ) 
$\delta 2.44$ (s, 3H), 2.49 (s, 3H), $3.48 \mathrm{dd}, J 16.2$ and $3.8 \mathrm{~Hz}$, $1 \mathrm{H}), 3.82(\mathrm{dd}, J 16.2$ and $9.1 \mathrm{~Hz}, 1 \mathrm{H}), 6.24(\mathrm{dd}, J 9.1$ and $3.8 \mathrm{~Hz}, 1 \mathrm{H}), 7.37-7.42(\mathrm{~m}, 1 \mathrm{H}), 7.46-7.53(\mathrm{~m}, 1 \mathrm{H})$, 7.53-7.58 (m, 2H), 7.77-7.82 (m, 2H), 7.91 (dd, J 2.0 and $0.7 \mathrm{~Hz}, 1 \mathrm{H}), 8.20(\mathrm{~d}, J 0.6 \mathrm{~Hz}, 1 \mathrm{H}) ;{ }^{13} \mathrm{C}$ NMR (APT, $\left.126.00 \mathrm{MHz}, \mathrm{CDCl}_{3}\right) \delta 0.62,20.68,35.42,78.99,119.25$, $119.92,120.16,120.63,121.15,122.16,123.79,124.50$, 124.99, 127.03, 128.71, 131.34, 132.74, 133.89, 135.91, $140.30,147.62,149.75,167.95,168.62$; HRMS (ESI) $m / z$, calcd. for $\mathrm{C}_{24} \mathrm{H}_{17} \mathrm{Cl}_{2} \mathrm{~N}_{3} \mathrm{NaO}_{5}[\mathrm{M}+\mathrm{Na}]^{+}:$520. 04375, found: 520.045130, $\Delta 2.7 \mathrm{ppm}$.

2-(1-(2,5-Dichlorophenyl)-1H-1,2,3-triazol-4-yl)-2,3-dihydronaphtho[2,3-b]furan-4,9-diyl diacetate (10h)

White solid, 49\% (24.2 mg) yield; mp $145-146^{\circ} \mathrm{C}$; IR (ATR) $v / \mathrm{cm}^{-1} 1775,1755,1662,1492,1446,1362,1258$, $1249,119,1170,1090,1045,764 ;{ }^{1} \mathrm{H}$ NMR $(500.00 \mathrm{MHz}$, $\left.\mathrm{CDCl}_{3}\right) \delta 2.46$ (bs, 6H), 3.59 (dd, $J 16.2$ and $4.9 \mathrm{~Hz}, 1 \mathrm{H}$ ), $3.84(\mathrm{dd}, J 16.2$ and $9.1 \mathrm{~Hz}, 1 \mathrm{H}), 6.26(\mathrm{dd}, J 9.1$ and $4.9 \mathrm{~Hz}, 1 \mathrm{H}), 7.37-7.39(\mathrm{~m}, 1 \mathrm{H}), 7.41(\mathrm{dd}, J 8.7$ and $2.5 \mathrm{~Hz}$, $1 \mathrm{H}), 7.47-7.50(\mathrm{~m}, 1 \mathrm{H}), 7.48(\mathrm{~d}, J 8.7 \mathrm{~Hz}, 1 \mathrm{H}), 7.61(\mathrm{~d}$, $J 2.6 \mathrm{~Hz}, 1 \mathrm{H}), 7.67-7.79(\mathrm{~m}, 1 \mathrm{H}), 8.13(\mathrm{~d}, J 6.9 \mathrm{~Hz}, 1 \mathrm{H})$; ${ }^{13} \mathrm{C}$ NMR (APT, $126.00 \mathrm{MHz}, \mathrm{CDCl}_{3}$ ) $\delta 20.60,20.64,35.21$, 78.92, 120.21, 120.86, 121.13, 123.69, 123.71, 124.40, 124.91, 126.94, 127.02, 127.82, 128.71, 130.77, 131.58, 133.56, 135.42, 140.15, 147.66, 148.38, 167.92, 168.33; HRMS (ESI) $\mathrm{m} / z$, calcd. for $\mathrm{C}_{24} \mathrm{H}_{17} \mathrm{Cl}_{2} \mathrm{~N}_{3} \mathrm{NaO}_{5}[\mathrm{M}+\mathrm{Na}]^{+}$: 520.4375, found: $520.043528, \Delta 0.4 \mathrm{ppm}$.

2-(1-Phenyl-1H-1,2,3-triazol-4-yl)-2,3-dihydronaphtho [1,2-b]furan-4,5-diyl diacetate (11a)

White solid, $87 \%$ (44.8 mg) yield; mp 163-164 ${ }^{\circ} \mathrm{C}$; IR (ATR) $\mathrm{v} / \mathrm{cm}^{-1} 1770,1504,1467,1370,1260,1214,1170$, $1042,911,758,688 ;{ }^{1} \mathrm{H}$ NMR $\left(500.00 \mathrm{MHz}, \mathrm{CDCl}_{3}\right) \delta 2.34$ (s, 3H), 2.45 (s, 3H), 3.63 (dd, $J 15.5$ and $6.8 \mathrm{~Hz}, 1 \mathrm{H}), 3.84$ (dd, $J 15.5$ and $9.8 \mathrm{~Hz}, 1 \mathrm{H}), 6.31(\mathrm{dd}, J 9.8$ and $6.8 \mathrm{~Hz}, 1 \mathrm{H})$, 7.41-7.46 (m, 2H), 7.47-7.52 (m, 3H), $7.71(\mathrm{~d}, J 7.6 \mathrm{~Hz}$, $2 \mathrm{H}), 7.76(\mathrm{~d}, J 8.1 \mathrm{~Hz}, 1 \mathrm{H}), 7.98(\mathrm{~d}, J 7.8 \mathrm{~Hz}, 2 \mathrm{H}), 8.07(\mathrm{~s}$, $1 \mathrm{H}$ ); ${ }^{13} \mathrm{C}$ NMR (APT, $75.0 \mathrm{MHz}, \mathrm{CDCl}_{3}$ ) $\delta 20.4,20.6,35.7$, 78.3, 114.2, 118.8, 119.9, 120.7, 121.5, 121.9, 125.7, 127.1, 127.6, 128.9, 129.7, 131.0, 136.7, 136.9, 149.1, 153.2, 167.8, 168.8; HRMS (ESI) $\mathrm{m} / z$, calcd. for $\mathrm{C}_{24} \mathrm{H}_{19} \mathrm{~N}_{3} \mathrm{NaO}_{5}$ $[\mathrm{M}+\mathrm{Na}]^{+}:$452.12169, found: 452.119707, $\Delta 4.4 \mathrm{ppm}$.

2-(1-(p-Tolyl)-1H-1,2,3-triazol-4-yl)-2,3-dihydronaphtho [1,2-b]furan-4,5-diyl diacetate (11b)

White solid, 64\% (25.4 mg) yield; mp 149-150 ${ }^{\circ} \mathrm{C}$; IR (ATR) $\mathrm{v} / \mathrm{cm}^{-1} 1769,1519,1456,1371,1260,1219,1170$, $1043,911,816,761 ;{ }^{1} \mathrm{H} \mathrm{NMR}\left(500.00 \mathrm{MHz}, \mathrm{CDCl}_{3}\right) \delta 2.34$ $(\mathrm{s}, 3 \mathrm{H}), 2.40(\mathrm{~s}, 3 \mathrm{H}), 2.45(\mathrm{~s}, 3 \mathrm{H}), 3.63(\mathrm{dd}, J 15.5$ and $7.0 \mathrm{~Hz}, 1 \mathrm{H}), 3.83(\mathrm{dd}, J 15.5$ and $9.8 \mathrm{~Hz}, 1 \mathrm{H}), 6.30(\mathrm{dd}$,
$J 9.8$ and $7.0 \mathrm{~Hz}, 1 \mathrm{H}), 7.29(\mathrm{~d}, J 8.1 \mathrm{~Hz}, 2 \mathrm{H}), 7.45$ (ddd, $J 8.3,6.9$ and $1.3 \mathrm{~Hz}, 1 \mathrm{H}$ ), 7.49 (ddd, $J 8.3,6.9$ and $1.4 \mathrm{~Hz}$, $1 \mathrm{H}), 7.58(\mathrm{~d}, J 8.5 \mathrm{~Hz}, 2 \mathrm{H}), 7.76(\mathrm{dd}, J 7.7$ and $1.0 \mathrm{~Hz}$, 1H), $7.98(\mathrm{dd}, J 7.7,1.0 \mathrm{~Hz}, 1 \mathrm{H}), 8.03(\mathrm{bs}, 1 \mathrm{H}) ;{ }^{13} \mathrm{C} \mathrm{NMR}$ (APT, 75.0 MHz, $\mathrm{CDCl}_{3}$ ) $\delta 20.6,20.8,21.3,35.9,78.6$, $114.4,119.0,120.1,120.8,121.7,122.1,125.8,127.3$, $127.8,130.4,131.1,132.7,134.9,136.9,149.2,153.5$, 168.0, 169.0; HRMS (ESI) $\mathrm{m} / z$, calcd. for $\mathrm{C}_{25} \mathrm{H}_{21} \mathrm{~N}_{3} \mathrm{NaO}_{5}$ $[\mathrm{M}+\mathrm{Na}]^{+}:$466.13734, found: 466.136028, $\Delta 2.9 \mathrm{ppm}$.

2-(1-(4-Methoxyphenyl)-1H-1,2,3-triazol-4-yl)-2,3-dihydronaphtho[1,2-b]furan-4,5-diyl diacetate (11c)

White solid, 75\% (36.8 mg) yield; mp 208-209 ${ }^{\circ} \mathrm{C}$; IR (ATR) $v / \mathrm{cm}^{-1} 1755,1520,1375,1256,1225,1206,1173$, 1046, 1031, 877, 832, 770; ${ }^{1} \mathrm{H}$ NMR $\left(500.00 \mathrm{MHz}, \mathrm{CDCl}_{3}\right)$ $\delta 2.34(\mathrm{~s}, 3 \mathrm{H}), 2.45(\mathrm{~s}, 3 \mathrm{H}), 3.62(\mathrm{dd}, J 15.5$ and $6.9 \mathrm{~Hz}$, $1 \mathrm{H}), 3.80-3.83(\mathrm{~m}, 1 \mathrm{H}), 3.85(\mathrm{~s}, 3 \mathrm{H}), 6.30(\mathrm{dd}, J 9.8$ and $6.9 \mathrm{~Hz}, 1 \mathrm{H}), 6.99(\mathrm{~d}, J 9.1 \mathrm{~Hz}, 2 \mathrm{H}), 7.45(\mathrm{ddd}, J 8.2,6.9$ and $1.4 \mathrm{~Hz}, 2 \mathrm{H}), 7.49(\mathrm{ddd}, J 8.2,6.9$ and $6.9 \mathrm{~Hz}, 1 \mathrm{H}), 7.60(\mathrm{~d}$, $J 9.1 \mathrm{~Hz}, 2 \mathrm{H}), 7.76(\mathrm{dd}, J 7.7$ and $0.8 \mathrm{~Hz}, 1 \mathrm{H}), 7.97-7.98$ (m, 2H); ${ }^{13} \mathrm{C}$ NMR (APT, $126.00 \mathrm{MHz}, \mathrm{CDCl}_{3}$ ) $\delta 20.41$, 20.53, 35.65, 55.60, 78.39, 114.21, 114.74, 118.82, 120.03, $121.49,121.93,122.31,125.63,127.06,127.62,130.36$, 130.91, 136.70, 148.90, 153.26, 159.90, 167.76, 168.82; HRMS (ESI) $m / z$, calcd. for $\mathrm{C}_{25} \mathrm{H}_{21} \mathrm{~N}_{3} \mathrm{NaO}_{6}[\mathrm{M}+\mathrm{Na}]^{+}$: 482.13226, found: $482.131008, \Delta 2.6 \mathrm{ppm}$.

2-(1-(4-Acetamidophenyl)-1H-1,2,3-triazol-4-yl)-2,3-dihydronaphtho[1,2-b]furan-4,5-diyl diacetate (11d)

White solid, 77\% (41.2 mg) yield; mp 208-209 ${ }^{\circ} \mathrm{C}$; IR (ATR) $v / \mathrm{cm}^{-1} 1772,1671,1522,1456,1370,1257,1215$, $1171,1042,905,834,763 ;{ }^{1} \mathrm{H}$ NMR $\left(300.00 \mathrm{MHz}, \mathrm{CDCl}_{3}\right)$ $\delta 2.16$ (s, 3H), 2.34 (s, 3H), 2.45 (s, 3H), 3.62 (dd, J 15.5 and $6.9 \mathrm{~Hz}, 1 \mathrm{H}), 3.81(\mathrm{dd}, J 15.5$ and $9.8 \mathrm{~Hz}, 1 \mathrm{H}), 6.28$ (dd, $J 9.7$ and $6.9 \mathrm{~Hz}, 1 \mathrm{H}), 7.41-7.51(\mathrm{~m}, 2 \mathrm{H}), 7.55$ (bs, 1H), $7.61(\mathrm{bs}, 5 \mathrm{H}), 7.75(\mathrm{dd}, J 7.1$ and $1.3 \mathrm{~Hz}, 1 \mathrm{H}), 7.95-$ 7.98 (m, 1H), 8.02 (bs, $1 \mathrm{H}$ ); ${ }^{13} \mathrm{C}$ NMR (APT, 75.0 MHz, $\left.\mathrm{CDCl}_{3}\right) \delta 20.4,20.6,24.5,35.6,78.3,114.2,118.8,119.9$, $120.4,121.3,121.5,121.9,127.2,127.6,130.9,132.7$, 136.7, 138.6, 148.9, 153.3, 167.8, 168.5, 169.0; HRMS (ESI) $\mathrm{m} / z$, calcd. for $\mathrm{C}_{26} \mathrm{H}_{22} \mathrm{~N}_{4} \mathrm{NaO}_{6}[\mathrm{M}+\mathrm{Na}]^{+}: 509.14316$, found: $509.141395, \Delta 4.5 \mathrm{ppm}$.

2-(1-(4-Fluorophenyl)-1H-1,2,3-triazol-4-yl)-2,3-dihydronaphtho[1,2-b]furan-4,5-diyl diacetate (11e)

White solid, 71\% (34.9 mg) yield; mp $184-186{ }^{\circ} \mathrm{C}$; IR (ATR) $v / \mathrm{cm}^{-1} 2927,1770,1518,1456,1370,1210$, 1171, 1110, 1041, 906, 838, 766; ${ }^{1} \mathrm{H}$ NMR $(500.00 \mathrm{MHz}$, $\left.\mathrm{CDCl}_{3}\right) \delta 2.34(\mathrm{~s}, \mathrm{H}), 2.45$ (s, 3H), 3.61 (dd, $J 15.5$ and $6.5 \mathrm{~Hz}, 1 \mathrm{H}), 3.84(\mathrm{dd}, J 15.5$ and $9.8 \mathrm{~Hz}, 1 \mathrm{H}), 6.30$ (dd, $J 9.8$ and $6.5 \mathrm{~Hz}, 1 \mathrm{H}), 7.18-7.21(\mathrm{~m} \mathrm{2H}), 7.45$ (ddd, $J$ 8.2, 
6.9 and $1.4 \mathrm{~Hz}, 1 \mathrm{H}), 7.49$ (ddd, $J$ 8.2, 6.9 and $1.4 \mathrm{~Hz}$, $1 \mathrm{H}), 7.67-7.70(\mathrm{~m}, 2 \mathrm{H}), 7.76(\mathrm{dd}, J 7.8$ and $0.7 \mathrm{~Hz}, 1 \mathrm{H})$, 7.97 (dd, $J 7.9$ and $0.7 \mathrm{~Hz}, 1 \mathrm{H}), 8.02(\mathrm{bs}, 1 \mathrm{H}) ;{ }^{13} \mathrm{C}$ NMR (APT, 75.0 MHz, $\mathrm{CDCl}_{3}$ ) $\delta$ 20.4, 20.5, 35.6, 78.2, 114.2, $116.7(\mathrm{~d}, J 23.2 \mathrm{~Hz}), 118.8,120.1,121.5,121.9,122.7$ (d, $J$ 8.6 Hz), 125.7, 127.1, 127.6, 131.0, $133.2(\mathrm{~d}, J 3.1 \mathrm{~Hz})$, 136.7, 149.3, 153.2, 162.4 (d, $J 247.5 \mathrm{~Hz}), 167.8,168.8$; HRMS (ESI) $m / z$, calcd. for $\mathrm{C}_{24} \mathrm{H}_{18} \mathrm{FN}_{3} \mathrm{NaO}_{5}[\mathrm{M}+\mathrm{Na}]^{+}$: 470.11227, found: $470.110268, \Delta 4.3 \mathrm{ppm}$.

2-(1-(4-Chlorophenyl)-1H-1,2,3-triazol-4-yl)-2,3-dihydronaphtho[1,2-b]furan-4,5-diyl diacetate (11f)

White solid, 67\% (34.2 mg) yield; $\mathrm{mp} 152-153{ }^{\circ} \mathrm{C}$; IR (ATR) $v / \mathrm{cm}^{-1} 3124,3081,2938,1765,1583,1503,1370$, 1250, 1209, 1169, 1040, 1009, 991, 966, 912, 872, 824, 760, 731, 702, 645, 622; ${ }^{\mathrm{H}} \mathrm{NMR}\left(500.00 \mathrm{MHz}, \mathrm{CDCl}_{3}\right)$ $\delta 2.34(\mathrm{~s}, 3 \mathrm{H}), 2.45(\mathrm{~s}, 3 \mathrm{H}), 3.60(\mathrm{dd}, J 15.5$ and $6.5 \mathrm{~Hz}$, $1 \mathrm{H}), 3.84(\mathrm{dd}, J 15.5$ and $9.8 \mathrm{~Hz}, 1 \mathrm{H}), 6.30$ (dd, $J 9.8$ and $6.5 \mathrm{~Hz}, 1 \mathrm{H}), 7.44-7.51(\mathrm{~m}, 2 \mathrm{H}), 7.47(\mathrm{~d}, J 8.9 \mathrm{~Hz}, 2 \mathrm{H}), 7.67$ $(\mathrm{d}, J 8.9 \mathrm{~Hz}, 2 \mathrm{H}), 7.76(\mathrm{~d}, J 8.0 \mathrm{~Hz}, 1 \mathrm{H}), 7.97(\mathrm{~d}, J 8.0 \mathrm{~Hz}$, 1H), 8.05 (bs, $1 \mathrm{H}$ ); ${ }^{13} \mathrm{C}$ NMR (APT, $126.00 \mathrm{MHz}, \mathrm{CDCl}_{3}$ ) $\delta$ 20.42, 20.55, 35.65, 78.21, 114.14, 118.82, 119.77, $121.53,121.77,121.88,125.70,127.13,127.66,129.90$, 131.00, 134.67, 135.38, 136.69, 149.42, 153.15, 167.78, 168.81; HRMS (ESI) $\mathrm{m} / z$, calcd. for $\mathrm{C}_{24} \mathrm{H}_{18} \mathrm{ClN}_{3} \mathrm{NaO}_{5}$ $[\mathrm{M}+\mathrm{Na}]^{+}:$486.08272, found: $486.081020, \Delta 3.5 \mathrm{ppm}$.

2-(1-(3,4-Dichlorophenyl)-1H-1,2,3-triazol-4-yl)-2,3-dihydronaphtho[1,2-b]furan-4,5-diyl diacetate (11 g)

White solid, $80 \%$ (35.1 mg) yield; $\mathrm{mp} 242-243^{\circ} \mathrm{C}$; IR (ATR) $v / \mathrm{cm}^{-1} 2923,1771,1583,1489,1456,1369,1210$, 1170, 1109, 1041, 906, 812, 764; ${ }^{1} \mathrm{H}$ NMR $(500.00 \mathrm{MHz}$, $\left.\mathrm{CDCl}_{3}\right) \delta 2.34$ (s, 3H), 2.45 (s, 3H), 3.59 (dd, $J 15.5$ and $6.4 \mathrm{~Hz}, 1 \mathrm{H}), 3.84$ (dd, $J 15.5$ and $9.8 \mathrm{~Hz}, 1 \mathrm{H}), 6.29$ (dd, $J 9.8$ and $6.4 \mathrm{~Hz}, 1 \mathrm{H}), 7.46$ (ddd, $J 8.1,6.9$ and $1.5 \mathrm{~Hz}, 1 \mathrm{H}), 7.50$ (ddd, $J 8.1,6.9$ and $1.5,1 \mathrm{H}), 7.57-7.59(\mathrm{~m}, 2 \mathrm{H}), 7.76(\mathrm{dd}$, $J 8.0$ and $1.5 \mathrm{~Hz}, 1 \mathrm{H}), 7.89-7.90(\mathrm{~m}, 1 \mathrm{H}), 7.97$ (dd, $J 8.0$ and $1.5 \mathrm{~Hz}, 1 \mathrm{H}), 8.05(\mathrm{~d}, J 0.6 \mathrm{~Hz}, 1 \mathrm{H}) ;{ }^{13} \mathrm{C}$ NMR (APT, $\left.126.00 \mathrm{MHz}, \mathrm{CDCl}_{3}\right) \delta 20.62,20.76,35.85,78.29,114.27$, 119.01, 119.70,119.92, 121.74, 122.06, 122.55, 125.95, 127.36, 127.87, 131.25, 131.63, 133.22, 134.19, 136.08, 136.87, 149.89, 153.29, 168.01, 169.02; HRMS (ESI) $\mathrm{m} / \mathrm{z}$, calcd. for $\mathrm{C}_{24} \mathrm{H}_{17} \mathrm{Cl}_{2} \mathrm{~N}_{3} \mathrm{NaO}_{5}[\mathrm{M}+\mathrm{Na}]^{+}: 520.04375$, found: 520.041544, $\Delta 4.2 \mathrm{ppm}$.

2-(1-(2,5-Dichlorophenyl)-1H-1,2,3-triazol-4-yl)-2,3-dihydronaphtho[1,2-b]furan-4,5-diyl diacetate (11h)

White solid, $>98 \%$ (44.4 mg) yield; $\mathrm{mp} 145-147^{\circ} \mathrm{C}$; IR (ATR) $v / \mathrm{cm}^{-1} 2924,1772,1489,1456,1369,1209,1170$, 1099, 1041, 906, 820, 765; ' $\mathrm{H}$ NMR $\left(500.00 \mathrm{MHz}, \mathrm{CDCl}_{3}\right)$ $\delta 2.34(\mathrm{~s}, 3 \mathrm{H}), 2.45(\mathrm{~s}, 3 \mathrm{H}), 3.67(\mathrm{dd}, J 15.5$ and $7.1 \mathrm{~Hz}$,
1H), 3.84 (dd, $J 15.5$ and $9.8 \mathrm{~Hz}, 1 \mathrm{H}), 6.32$ (dd, $J 9.8$ and $7.1 \mathrm{~Hz}, 1 \mathrm{H}), 7.42(\mathrm{dd}, J 8.6$ and $2.4 \mathrm{~Hz}, 1 \mathrm{H}), 7.45-7.51$ $(\mathrm{m}, 2 \mathrm{H}), 7.50(\mathrm{~d}, J 8.6 \mathrm{~Hz}, 1 \mathrm{H}), 7.65(\mathrm{dd}, J 7.9$ and $1.4 \mathrm{~Hz}$, $1 \mathrm{H}), 7.76(\mathrm{dd}, J 7.7$ and $1.4 \mathrm{~Hz}, 1 \mathrm{H}), 7.97(\mathrm{dd}, J 7.7$ and $1.4 \mathrm{~Hz}, 1 \mathrm{H}$ ), $8.91(\mathrm{~s}, 1 \mathrm{H}) ;{ }^{13} \mathrm{C}$ NMR (APT, $126.0 \mathrm{MHz}$, $\left.\mathrm{CDCl}_{3}\right) \delta 20.63,20.76,35.80,78.41,114.37,119.03$, $121.72,122.10,123.78,125.89,127.07,127.07,127.30$, $127.85,128.08,131.08,131.22,131.82,133.90,135.60$, 136.89, 148.66, 153.43, 167.93, 169.01; HRMS (ESI) $\mathrm{m} / \mathrm{z}$, calcd. for $\mathrm{C}_{24} \mathrm{H}_{17} \mathrm{Cl}_{2} \mathrm{~N}_{3} \mathrm{NaO}_{5}[\mathrm{M}+\mathrm{Na}]^{+}: 520.4375$, found: 520.044751, $\Delta 1.9 \mathrm{ppm}$.

\section{Biological assays}

\section{Materials}

The Caco-2 and Vero cell lines were purchased from the Rio de Janeiro Cell Bank, Brazil. Dulbecco's Modified Eagles Medium (DMEM), Ross Park Memorial Institute Medium (RPMI-1640), Hank's Balanced Salt Solution (HBSS), fetal bovine serum (FBS), antibiotic solution $\left(10,000 \mathrm{U} \mathrm{mL}\right.$ penicillin and $10 \mathrm{mg} \mathrm{mL}^{-1}$ streptomycin), antifungal solution (25-30 $\mu \mathrm{g} \mathrm{mL}^{-1}$ amphotericin B), trypsin-ethylenediaminetetraacetic acid (EDTA) solution ( $2.5 \mathrm{mg} \mathrm{mL}^{-1}$ trypsin, $0.2 \mathrm{mg} \mathrm{mL}^{-1}$ EDTA) and 3-(4,5-dimethylthiazol-2-yl)-2,5-diphenyltetrazolium bromide (MTT) were all supplied by Sigma-Aldrich (São Paulo, Brazil). Dimethyl sulfoxide (DMSO) and other reagents are of analytical grade supplied by Sigma-Aldrich (São Paulo, Brazil).

\section{Cell culture conditions}

Cells were maintained in DMEM supplemented with $4.5 \mathrm{mg} \mathrm{mL}^{-1}$ glucose, $0.1 \mathrm{mg} \mathrm{mL}^{-1}$ penicillin, $0.14 \mathrm{mg} \mathrm{mL}^{-1}$ streptomycin and $10 \%$ inactivated FBS. Cultured cells were maintained at $37{ }^{\circ} \mathrm{C}$ in an atmosphere containing 95\% air and $5 \% \mathrm{CO}_{2}$. Cells were sub-cultivated every $48 \mathrm{~h}$ by trypsin-EDTA solution.

\section{Cytotoxicity by MTT assay}

Metabolically active cells were assessed using the MTT reduction colorimetric assay, as reported by Mosmann ${ }^{25}$ and Alley et al. ${ }^{26}$ Cells were seeded in 96-well plates (Corning, Sigma-Aldrich, São Paulo, Brazil) at density of 32,000 cells per well, distributed in a total volume of $200 \mu \mathrm{L}$ per well. Plates were taken to cell incubator at $37^{\circ} \mathrm{C}$ and $5 \% \mathrm{CO}_{2}$ for $24 \mathrm{~h}$. After incubation, cells were placed in contact with the samples ( 0.5 to $50 \mu \mathrm{M}$ ) for $48 \mathrm{~h}$. Samples were solubilized in 10\% FBS DMEM or RPMI containing $0.5 \%$ of DMSO. The control group was represented by the mixture between the culture media and DMSO $(0.5 \%)$. The samples were aspirated and treated with MTT reagent 
by adding $100 \mu \mathrm{L}$ of HBSS and $25 \mu \mathrm{L}$ of MTT solution (2.5 $\mathrm{mg} \mathrm{mL}^{-1}$ ) per well. The plates containing the cells were incubated with MTT for $3 \mathrm{~h}$ at $37{ }^{\circ} \mathrm{C}$ and $5 \% \mathrm{CO}_{2}$. At the end of incubation time, MTT reagent was aspirated, and cells were washed with phosphate-buffered saline (PBS) solution ( $\mathrm{pH}$ 7.4). PBS was then aspirated and $100 \mu \mathrm{L}$ per well of DMSO were added to break cell membrane and solubilize formazan crystals. The absorbance readings were performed in Microplate Absorbance Reader iMARK ${ }^{\mathrm{TM}}$ (Bio-Rad Laboratories Srl, Segrate, Italy), with reference to 570 and $690 \mathrm{~nm}$ after vigorous shaking for $60 \mathrm{~s} .^{25,26}$

Cytotoxicity was expressed as the percentage of cells surviving after treatment with samples in comparison to untreated cells. Drug concentration required to inhibit cell growth by $50 \%\left(\mathrm{IC}_{50}\right.$ for tumor cells and $\mathrm{CC}_{50}$ for Vero cells) and selectivity index (SI) were calculated with GraphPad Prism 5. ${ }^{27}$

\section{In vitro hemocompatibility studies}

The authors state that they have obtained appropriate institutional review board approval or have followed the principles outlined in the Declaration of Helsinki for all human or animal experimental investigations. In addition, for investigations involving human subjects, informed consent has been obtained from the participants involved. Human blood samples were obtained from healthy volunteers between 18 and 35 years, who did not use drugs or any other substances that could affect the trials for at least 15 days following the rules of the Human Research Ethics Committee from Rio de Janeiro Federal University (ID number: 3.807.671).

Hemocompatibility of acetylated derivatives with antitumor activity (10a, 11c, 11g and 11e) was performed by platelet aggregation, prothrombin time (PT), activated partial thromboplastin time (aPTT) and hemolysis tests. Platelet aggregation test was performed using the turbidimetric method with the Chronolog ${ }^{\circledR}$ Model 560 luminosity aggregator (Chrono-Log Corporation, Havertown, PA, USA). For this assay, the derivatives $(100 \mu \mathrm{M})$ were pre-incubated at $37^{\circ} \mathrm{C}$ for $2 \mathrm{~min}$ in platelet-rich plasma (PRP) with subsequent addition of the adenosine-5' -diphosphate $3 \mu \mathrm{M}$ (ADP) to obtain maximum platelet aggregation (Cayman Chemical Co., Inc., Ann Arbor, MI, USA). ${ }^{28}$

In the hemolysis assay, erythrocytes were washed 3 times with phosphate-buffered saline (PBS) at $\mathrm{pH} 7.4$ by centrifugation. Subsequently, the derivatives $(100 \mu \mathrm{M})$ were incubated with erythrocyte suspension at $37^{\circ} \mathrm{C}$ for $3 \mathrm{~h}$ and the release of hemoglobin was determined by the optical density in the supernatant at $540 \mathrm{~nm}$, with hemocompatible values $\leq 10 \%$. The assay was performed in triplicate and
1\% Triton X-100 (Sigma-Aldrich, Saint Louis, USA) was used as a positive control. ${ }^{29-31}$

PT and aPTT assays were performed using citrated platelet-poor plasma (PPP) in the CoagLab ${ }^{\circledR}$ IV coagulation analyzer (Beijing Shining Sun Technology Co., Ltd., China) according to manufacturer's protocol (Diagnostica-Stago Inc., Parsippany, NJ, USA) and the coagulant profile was expressed in T1/T0, which is the ratio between test and control time in second..$^{32,33}$

\section{Molecular docking}

The three-dimensional structures of the DNA-binding domain of human topoisomerase I, topoisomerase II $\alpha$ and II $\beta$ were retrieved from the Protein Data Bank (PDB) under the codes $1 \mathrm{~K} 4 \mathrm{~T},{ }^{34} 5 \mathrm{GWK}^{35}$ and $3 \mathrm{QX} 3,{ }^{36}$ respectively. The structure of the ATPase domain of the human topoisomerase II $\alpha$ was obtained with the PDB code 1 ZXM. ${ }^{37}$

Meanwhile, the three-dimensional structures of the enantiomers $S$ and $R$ of the compounds 11c, 11g and 11e were constructed and optimized using the Spartan' $10^{38}$ software (Wavefunction Inc. Irvine, CA, USA). First, we performed a conformational analysis in a vacuum using the MMFF force field. Then, the lowest-energy conformer was submitted to a geometry optimization using the RM1 semiempirical method. Finally, the structure was subjected to a single point $a b$ initio calculation using the Hartree-Fock method with the $6-31 \mathrm{G} *$ basis set.

Docking studies were performed using Autodock Tools 1.5.7 (ADT) ${ }^{39}$ and Autodock Vina 1.1.2. ${ }^{40}$ Polar hydrogens and Gasteiger charges were added to the protein using ADT. This software was also employed to set the torsional bonds of the ligands while the proteins were kept rigid. The docking protocols used herein have been validated previously by our research group and are described elsewhere. ${ }^{24}$ The lowest-energy binding pose was selected for protein-ligand interaction analysis using Pymol v. $1.2 \mathrm{r} 2 .^{41}$

\section{Statistical analysis}

Cytotoxicity results (average and standard deviation) were statistically evaluated in Sigma Plot 12.5 software. $^{42}$ The $t$-test was used for comparative evaluations of these results where a $p$-value $\leq 0.05$ was considered statistically significant. The statistical analysis of hemocompatibility studies was performed with analysis of variance (ANOVA) followed by Tukey's test in the Graphpad Prism 8.027 software with significant value $p \leq 0.05$. All results were expressed as the mean \pm standard deviation. 


\section{Results and Discussion}

\section{Chemistry}

Initially, we prepared naphthoquinone-1H-1,2,3-triazoles hybrids $8 \mathbf{a}-\mathbf{8 h}$ and $9 \mathbf{a}-9 \mathbf{h}$ by oxidative cycloaddition reaction between lawsone (6) and 4-vinyl-1 $\mathrm{H}$-1,2,3-triazoles $\mathbf{7 a - 7 \mathbf { h } ^ { 4 3 }}$ promoted by ceric ammonium nitrate $(\mathrm{CAN})$ in alkaline medium as we previously described (Scheme 1). ${ }^{24}$ Then, the reductive acetylation of the quinones in excess of metallic zinc and acetic anhydride allowed to obtain sixteen dihydronaphthofurandiyl diacetate 10a-10h and 11a-11h in very good yields (Scheme 1). It should be noted that 8d and 9d nitrated naphthoquinones suffered a reduction in the $\mathrm{NO}_{2}$ group with subsequent acetylation of the resulting $\mathrm{NH}_{2}$ group, generating the $N$-acetylated derivatives $10 d$ and 11d.

In general, we did not observe any significant influence of the $\mathrm{R}$ group in the phenyl ring on the yield of the reactions to obtain 10a-10h and 11a-11h (Table 1).

Table 1. Synthesis of dihydronaphthofurandiyl diacetate 10a-10h and 11a-11h

\begin{tabular}{lcccc}
\hline $\mathrm{R}$ & $\mathbf{1 0}$ & $\eta / \%$ & $\mathbf{1 1}$ & $\eta / \%$ \\
\hline $\mathrm{H}$ & $\mathbf{1 0 a}$ & 93 & $\mathbf{1 1 a}$ & 87 \\
$4-\mathrm{CH}_{3}$ & $\mathbf{1 0 b}$ & 84 & $\mathbf{1 1 b}$ & 64 \\
$4-\mathrm{OCH}_{3}$ & $\mathbf{1 0 c}$ & 53 & $\mathbf{1 1 c}$ & 75 \\
$4-\mathrm{NHAc}$ & $\mathbf{1 0 d}$ & 88 & $\mathbf{1 1 d}$ & 77 \\
$4-\mathrm{F}$ & $\mathbf{1 0 e}$ & 44 & $\mathbf{1 1 e}$ & 71 \\
$4-\mathrm{Cl}$ & $\mathbf{1 0 f}$ & 84 & $\mathbf{1 1 f}$ & 67 \\
$3,4-d i \mathrm{Cl}$ & $\mathbf{1 0 g}$ & 93 & $\mathbf{1 1 g}$ & 80 \\
$2,5-d i \mathrm{Cl}$ & $\mathbf{1 0 h}$ & 49 & $\mathbf{1 1 h}$ & 98 \\
\hline
\end{tabular}

$\eta$ : isolated yield.

The compounds structures were confirmed by spectroscopic techniques (see Experimental and Supplementary Information sections). In the ${ }^{1} \mathrm{H}$ NMR spectrum analysis of compound $\mathbf{1 0 e}$, it could be observed two singlets at 2.44 and 2.48 ppm for methyl of acetyl groups and the double doublets at $3.51 \mathrm{ppm}(\mathrm{dd}, J 16.1$ and $4.1 \mathrm{~Hz}, 1 \mathrm{H})$ and $3.82 \mathrm{ppm}(\mathrm{dd}, J 16.1$ and $9.1 \mathrm{~Hz}$, $1 \mathrm{H})$ corresponding to $\mathrm{H}-3$ protons; it was also observed a double doublet at $6.25 \mathrm{ppm}(\mathrm{dd}, J 9.1$ and $4.1 \mathrm{~Hz}$, $1 \mathrm{H})$ corresponding to $\mathrm{H}-2$ proton. The four doublets at $116.6 \mathrm{ppm}\left(\mathrm{d}, J_{\mathrm{C}-\mathrm{F}} 23.2 \mathrm{~Hz}\right), 122.4 \mathrm{ppm}\left(\mathrm{d}, J_{\mathrm{C}-\mathrm{F}} 8.6 \mathrm{~Hz}\right)$, $133.2 \mathrm{ppm}\left(\mathrm{d}, J_{\mathrm{C}-\mathrm{F}} 3.1 \mathrm{~Hz}\right)$ and $162.4 \mathrm{ppm}\left(\mathrm{d}, J_{\mathrm{C}-\mathrm{F}} 248.9 \mathrm{~Hz}\right)$ in ${ }^{13} \mathrm{C}$ NMR (APT type) confirm the presence of the 4-fluorophenyl group. On the other hand, in the ${ }^{1} \mathrm{H}$ NMR spectrum of 11e, it can be observed two singlets at 2.34 and 2.35 for methyl of acetyl groups and two double doublets at $3.61 \mathrm{ppm}(\mathrm{dd}, J 15.5$ and $6.5 \mathrm{~Hz}, 1 \mathrm{H})$ and $3.84(\mathrm{dd}$, $J 15.5$ and $9.8 \mathrm{~Hz}, 1 \mathrm{H}$ ) corresponding to $\mathrm{H}-3$ protons; it was also observed a double doublet at $6.30 \mathrm{ppm}$ (dd, $J 9.8$ and $6.5 \mathrm{~Hz}, 1 \mathrm{H}$ ), corresponding to $\mathrm{H}-2$ proton. Similarly, the four doublets at $116.7\left(\mathrm{~d}, J_{\mathrm{C}-\mathrm{F}} 23.2 \mathrm{~Hz}\right), 122.7\left(\mathrm{~d}, J_{\mathrm{C}-\mathrm{F}}\right.$ $8.6 \mathrm{~Hz}), 133.2\left(\mathrm{~d}, J_{\mathrm{C}-\mathrm{F}} 3.1 \mathrm{~Hz}\right)$ and $162.4\left(\mathrm{~d}, J_{\mathrm{C}-\mathrm{F}} 247.5 \mathrm{~Hz}\right)$ in ${ }^{13} \mathrm{C}$ NMR (APT type) confirm that the molecule is also fluorinated. Moreover, in the aromatic region, the singlet at $8.14 \mathrm{ppm}$ assigned to the resonance of the $\mathrm{H}-5$ ' proton for isomer 10e and at $8.02 \mathrm{ppm}$ for $\mathbf{1 1 e}$, a very characteristic signal of the proton resonance of triazolic ring $\mathrm{CH}$.

\section{Biological assays}

\section{Cytotoxicity by MTT assay}

The dihydronaphthofurandiyl diacetate1H-1,2,3-triazoles hybrids $\mathbf{1 0 a - 1 0 h}$ and 11a-11h were screened for in vitro activity and the Caco- 2 cells $\mathrm{IC}_{50}$ assays were carried out only with compounds with high toxicity profile (cell viability decreased by at least 50\%) and simultaneously Vero cells viability above $70 \%$, which meets the criteria defined by ISO 10993:5. ${ }^{44}$ All acetylated derivatives were not cytotoxic to Vero cells in screening tests at $5 \mu \mathrm{M}$. Derivatives 11c, 10a, 11g and 11e were chosen for determine the selectivity index using the cell viability criterion \pm standard deviation $\leq 50 \%$ (Table 2 ).

The compound $9 \mathbf{e}$, synthetic precursor of 11e described in our previous work, ${ }^{24}$ was cytotoxic to Vero cells on that

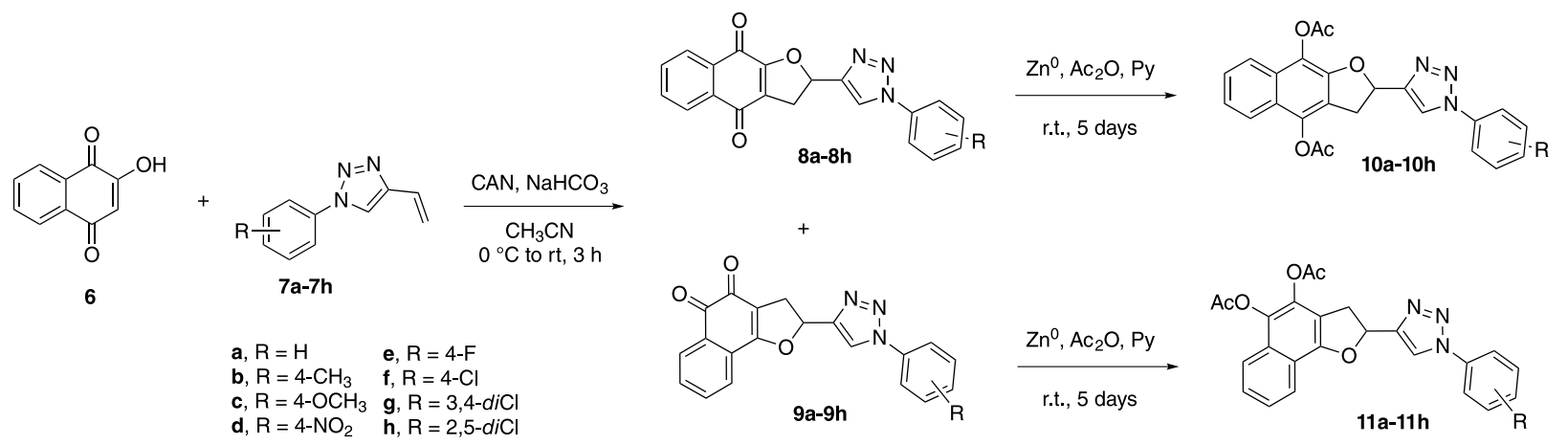

Scheme 1. Synthetic route for the synthesis of dihydronaphthofurandiyl diacetate 10a-10h and 11a-11h. 
Table 2. Cell viability of Caco-2 and Vero cells after $48 \mathrm{~h}$ of exposition to compounds at $5 \mu \mathrm{M}$ in screening tests; $\mathrm{CC}_{50}$ and $\mathrm{IC}_{50}$ of most active derivatives (cell viability \pm standard deviation $<50 \%$ ) against Caco- 2 cells

\begin{tabular}{|c|c|c|c|c|c|c|}
\hline \multirow{2}{*}{ entry } & \multirow{2}{*}{ Compound } & \multicolumn{2}{|c|}{ Vero cells } & \multicolumn{2}{|c|}{ Caco- 2 cells } & \multirow{2}{*}{ SI } \\
\hline & & Cell viability ${ }^{\mathrm{a}} \%$ & $\mathrm{CC}_{50} / \mu \mathrm{M}$ & Cell viability ${ }^{\mathrm{a}} \%$ & $\mathrm{IC}_{50} / \mu \mathrm{M}$ & \\
\hline 1 & $10 \mathrm{a}$ & $101.2 \pm 6.7$ & $25.9 \pm 7.0$ & $37.9 \pm 3.3$ & N/A & N/A \\
\hline 2 & $10 \mathrm{~b}$ & $104.1 \pm 3.8$ & - & $122.1 \pm 33.4$ & - & \\
\hline 3 & $10 \mathrm{c}$ & $106.2 \pm 6.2$ & - & $91.9 \pm 18.8$ & - & \\
\hline 4 & 10d & $105.1 \pm 13.9$ & - & $97.2 \pm 7.1$ & - & \\
\hline 5 & $10 \mathrm{e}$ & $98.5 \pm 3.4$ & - & $89.7 \pm 4.5$ & - & \\
\hline 6 & $10 f$ & $103.7 \pm 4.3$ & - & $109.4 \pm 30.2$ & - & \\
\hline 7 & $10 \mathrm{~g}$ & $102.4 \pm 7.5$ & - & $145.8 \pm 4.2$ & - & \\
\hline 8 & $10 \mathrm{~h}$ & $95.4 \pm 12.8$ & - & $95.2 \pm 30.4$ & - & \\
\hline 9 & 11a & $102.3 \pm 2.5$ & - & $71.3 \pm 4.4$ & - & \\
\hline 10 & $11 b$ & $102.6 \pm 8.9$ & - & $111.5 \pm 15.8$ & - & \\
\hline 11 & $11 \mathrm{c}$ & $103.6 \pm 19.7$ & $9.2 \pm 3.4$ & $20.2 \pm 2.5$ & $24.6 \pm 9.7$ & 0.4 \\
\hline 12 & 11d & $98.2 \pm 6.6$ & - & $139.8 \pm 7.5$ & - & \\
\hline 13 & $11 \mathrm{e}$ & $96.7 \pm 3.2$ & $29.5 \pm 1.8$ & $56.6 \pm 7.5$ & $7.2 \pm 0.2$ & 4.1 \\
\hline 14 & $11 f$ & $106.3 \pm 3.5$ & - & $97.5 \pm 3.3$ & - & \\
\hline 15 & $11 \mathrm{~g}$ & $106.9 \pm 6.8$ & $63.0 \pm 9.1$ & $53.1 \pm 6.5$ & $32.6 \pm 1.0$ & 1.9 \\
\hline 16 & $11 \mathrm{~h}$ & $99.6 \pm 3.3$ & - & $67.9 \pm 4.0$ & - & \\
\hline
\end{tabular}

The compounds were used at $5 \mu \mathrm{M}$ in screening tests. SI: selectivity index $\left(\mathrm{CC}_{50 \text { Vero }} / \mathrm{IC}_{50 \mathrm{Caco}-2}\right)$; data are presented as mean \pm standard deviation; N/A: not available, due to stability problems during experiments with sample of compound $10 \mathrm{a} ; \mathrm{IC}_{50}$ : half-maximal inhibitory concentration; $\mathrm{CC}_{50}: 50 \%$ cytotoxic concentration.

occasion (cell viability $=55.8 \pm 1.8 \%$ ), but the acetylated derivative 11e did not showed cytotoxicity in Vero cells in the present work $(96.7 \pm 3.2 \%)$, under the same conditions, showing a selectivity index of 4.1. Interestingly, in the previous work ${ }^{24}$ the compound with the highest selectivity was 9a (SI 6.25) which is also an ortho-naphthoquinone as 9e. Although it had a higher SI than derivative 11e, cytotoxicity demonstrated a higher risk for Vero cells at $5 \mu \mathrm{M}$.

Among six derivatives with the greatest reduction in the viability of Caco-2 cells in the initial screening $(5 \mu \mathrm{M})$, entries $1,9,11,13,15$ and 16 (Table 2), five of the compounds 11a, 11c, 11e, 11g and 11h are prototype derivatives of ortho-naphthoquinone and only the compound 10a is a prototype derivative of paranaphthoquinone of this set reinforcing a better performance of ortho-naphthoquinone in two different works of the same authors. ${ }^{19,24}$

\section{In vitro hemocompatibility studies}

The platelet aggregation assay reveals no statistical significance ( $p \geq 0.05$ ) for compounds 10a, 11c, 11g and 11e, since it did not express antiplatelet activity induced by ADP indicating the hemocompatible potential of these compounds $(72.87 \pm 4.67,80.00 \pm 11.1,100.0 \pm 0.00$ and $97.67 \pm 4.04 \%$, respectively, Figure 2a).

These hybrids also have no anticoagulant activity against the extrinsic and intrinsic pathways of the coagulation cascade ( $p \geq 0.05)$ through PT and aPTT assays exhibiting no increase in the ratio between the coagulation time of derivatives and the control (DMSO 1\%, Figures 2c and 2d).

In parallel, the derivatives did not show a hemolytic profile $(p \leq 0.05)$ after $3 \mathrm{~h}$ of incubation at $37{ }^{\circ} \mathrm{C}$ with hemolysis values from $0.0 \pm 0.00$ to $1.6 \pm 1.18 \%$. Based on Fisher et al. ${ }^{30}$ that showed hemolysis results $10 \%$ or less may considered non-hemolytic, suggesting greater safety and less toxicity to our acetylated derivatives (Figure 2b).

\section{Docking of the most potent compounds with topoisomerase I,} $\| \alpha$ and $\| \beta$

As our previous work suggested ${ }^{24}$ and we already mentioned above, many naphthoquinones are known for inhibiting topoisomerase enzymes, ${ }^{10-12}$ thus we decided to evaluate the potential of our new naphthoquinone derivatives to target the topoisomerases. We docked the most potent derivatives 11c, 11g and 11e with human topoisomerase I and topoisomerase II isoforms. Docking results suggested that the $S$ enantiomers of these compounds are the main responsible for their binding to the enzymes. Consequently, we explored the binding mode of this enantiomer with topoisomerases more in-depth henceforth.

Interestingly, we did not observe the 2,3-dihydronaphtho[1,2-b]furan-4,5-diyl diacetate moiety of any compound intercalating with the nitrogen-containing bases of the DNA bound to topoisomerase I (data not shown). 

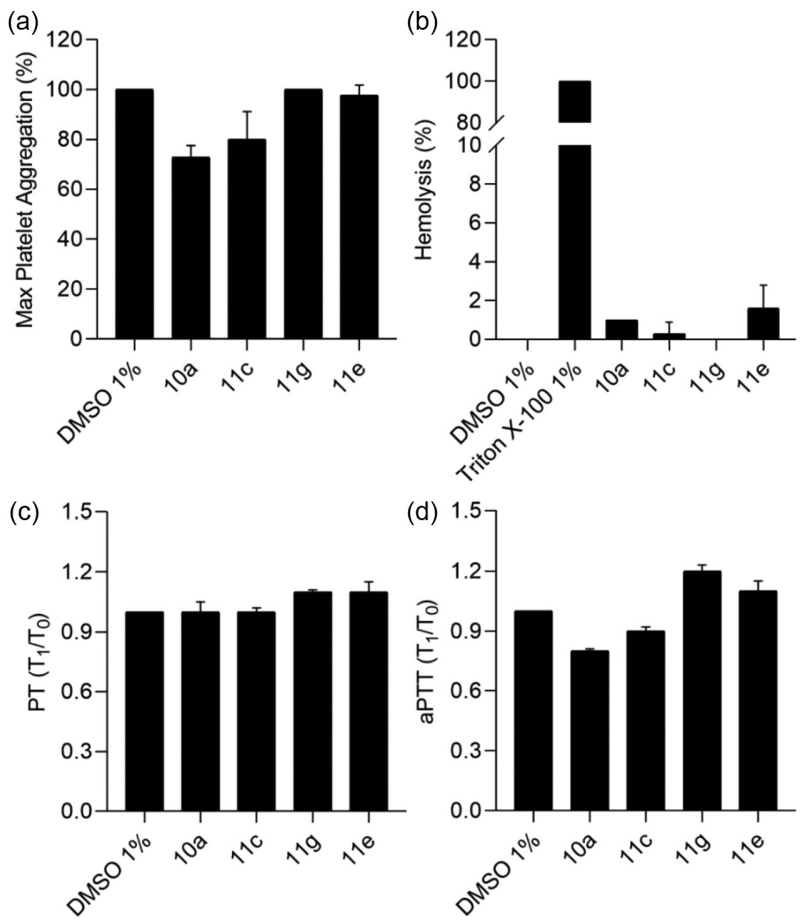

Figure 2. Hemocompatibility assessment. For all systems 1\% DMSO is the negative control. (a) Platelet aggregation assay. (b) Hemolysis assay, which Triton X-100 1\% is the positive control. (c) Prothrombin time (PT) test. (d) Activated partial thromboplastin (aPTT) test. $\mathrm{T}_{1} / \mathrm{T}_{0}$ is the ratio between test and control time in seconds.

These results suggested that these isomers are not able to inhibit this enzyme, similarly its carbonylated precursors as previously shown by us. ${ }^{24}$

On the other hand, we have shown that a related non-acetylated compound did not intercalate into the DNA base pairs within the DNA-binding domain of topoisomerase II $\beta .{ }^{24}$ However, the acetylation of these derivatives led to binding poses like the one observed for etoposide, a well-known inhibitor (Figure 3). The naphthalene moiety of all compounds was stacked between the $+4 \mathrm{~A} /+1 \mathrm{~T}$ and $+5 \mathrm{G} /-1 \mathrm{C}$ base pairs, like the polycyclic ring system of etoposide. Compounds 11c and 11g bound with their triazole and phenyl groups positioned towards the DNA major groove where the glycosidic group of the inhibitor was positioned. As a result, they were involved in a van der Waals contact with M782. In contrast, the phenyl and triazole moieties of 11e were placed towards the DNA minor group like the ring $\mathrm{E}$ of the inhibitor. Thereby, it established a cation- $\pi$ interaction with R503 and a van der Waals contact with Q778. Likewise, the other compounds also interacted with R503, either by hydrogen-bond (e.g., 11c) or van der Waals interaction (e.g., 11g). Interestingly, etoposide and other inhibitors are known to explore a similar interaction network with this enzyme. ${ }^{45}$

Furthermore, we also evaluated their binding modes with the DNA-binding domain of topoisomerase II $\alpha$ (Figure 4). Only compounds 11c and 11e intercalated between the $+4 \mathrm{~A} /+1 \mathrm{~T}$ and $+5 \mathrm{G} /-1 \mathrm{C}$ base pairs, suggesting that these compounds could inhibit this enzyme like etoposide and warrant higher cytotoxic activity compared with 11g. Their triazole and phenyl group bound to different regions of the enzyme. For instance, these groups of 11c and 11e were positioned towards the DNA major and minor grooves, respectively, exploring similar regions as observed for the glycosidic group and $\mathrm{E}$ ring of etoposide. Because of this, the 4-methoxyphenyl ring of 11c interacted with M762 and R804, whereas the 4-fluorophenyl of 11e was involved in van der Waals interaction with S464. Besides, the 2,3-dihydronaphtho[1,2-b]furan-4,5-diyl diacetate moiety of 11e established a hydrogen-bond with R487, in addition
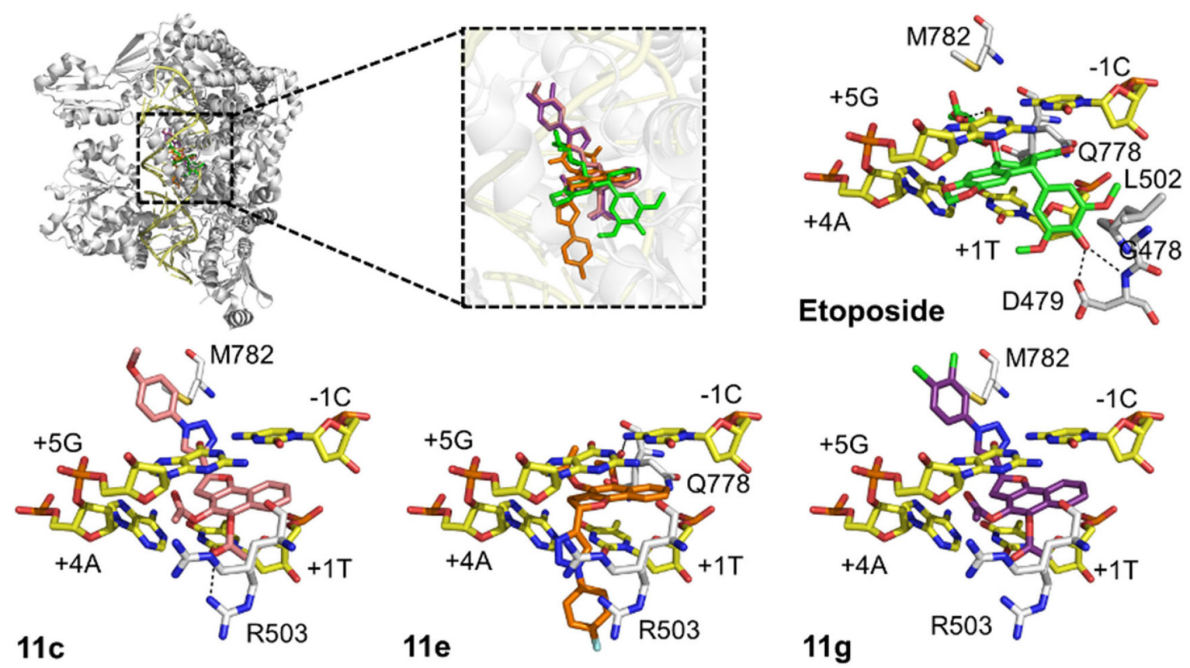

Figure 3. Binding mode of compounds 11c (pink), 11e (orange), and 11g (purple) with the DNA-binding domain of topoisomerase II $\beta$ and comparison with the binding mode of the known inhibitor etoposide (green). The carbon atoms of the amino acid residues are shown in white, while the carbon atoms of the DNA are shown in yellow. Hydrogen bonds are represented as dashed lines. 


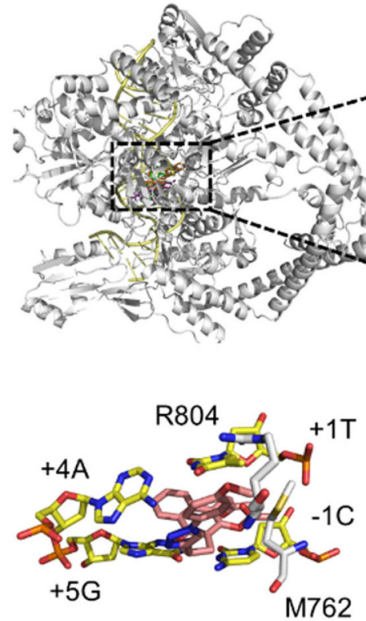

11c

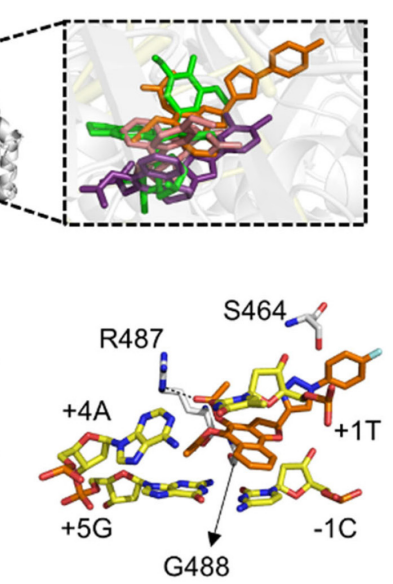

$11 \mathrm{e}$
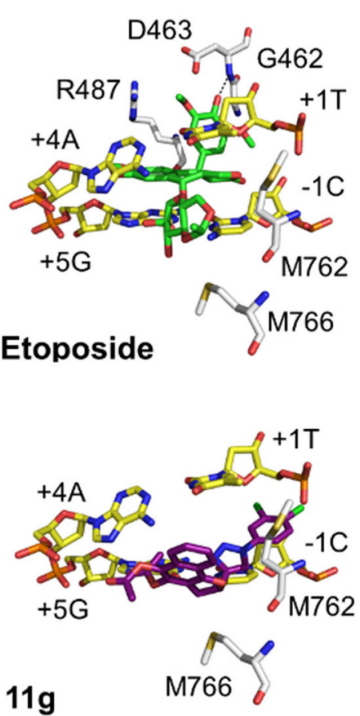

Figure 4. Docking of compounds 11c (pink), 11e (orange), 11g (purple) and with the DNA-binding domain of topoisomerase II $\alpha$ and comparison with the binding mode of the known inhibitor etoposide (green). The carbon atoms of the amino acid residues are shown in white, while the carbon atoms of the DNA are shown in yellow. Hydrogen bonds are represented as dashed lines.

to a van der Waals interaction with G488, which could help to anchor this moiety between the base pairs.

Meanwhile, we investigated whether these compounds could bind to the ATPase domain of topoisomerase II $\alpha$, as well (Figure 5). Compounds 11c and 11g did not bind to the ATP binding site, interacting with residues at its entrance only. On the other hand, compound 11e exhibited a binding manner like the one observed for the inhibitor AMP-PNP. For this compound, the 2,3-dihydronaphtho[1,2-b]furan4,5-diyl diacetate moiety bound at the entrance of the cavity, interacting with S149 by hydrogen-bonding and R98, N120, I141, and F142 via van der Waals contacts. The triazole and phenyl rings were positioned deeper in this cavity, exploring similar interactions as observed for the sugar and imidophosphate groups of the known inhibitor. ${ }^{37}$ For example, the triazole group was involved in van der Waals contacts with N91, A167, and K168, while the phenyl ring interacted with R162, N163, and G164. As well, the related quinonoid derivative resembled the inhibitor binding pose, conserving a similar interaction pattern. ${ }^{24}$

Many topoisomerase II inhibitors target both the $\alpha$ and $\beta$ isoforms of this enzyme. The inhibition of topoisomerase II $\beta$ is associated with the side effects of these compounds. ${ }^{46}$ Indeed, we observed that the acetylated
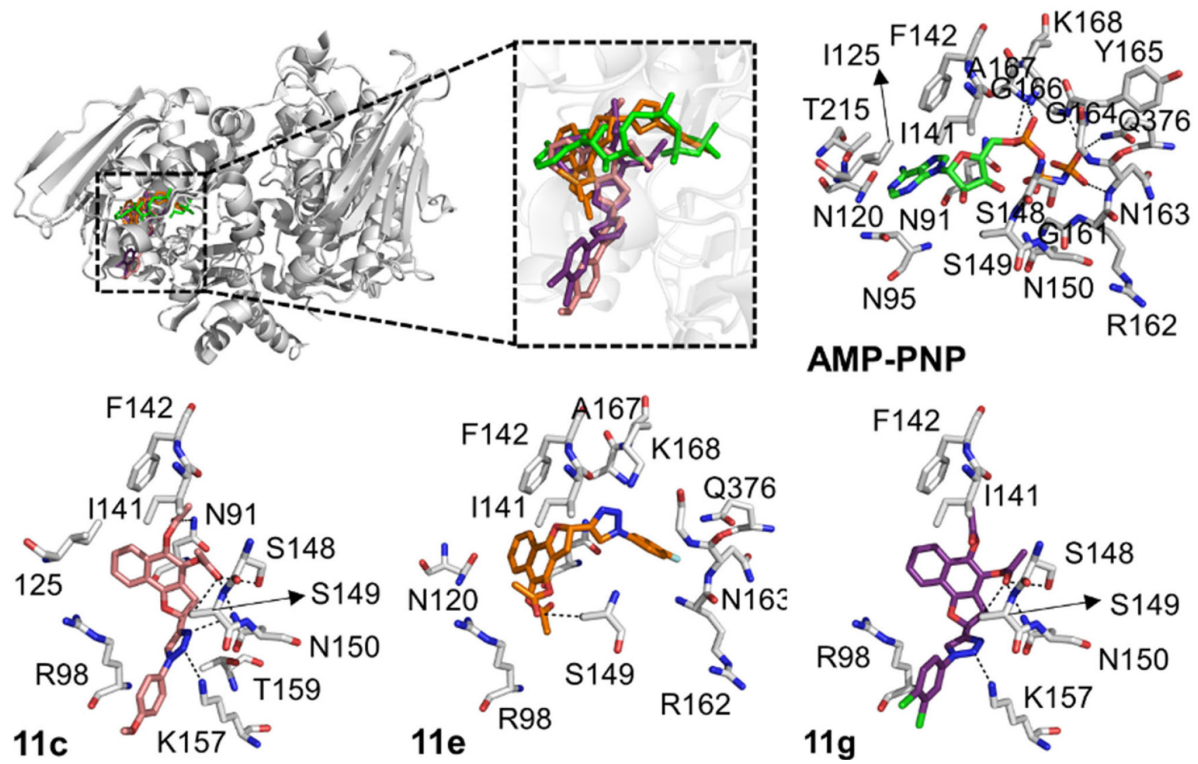

Figure 5. Binding mode of compounds 11c (pink), 11e (orange), and $11 \mathrm{~g}$ (purple) with the ATPase domain of topoisomerase II $\alpha$ and comparison with the binding mode of the known inhibitor AMP-PNP (green). The carbon atoms of the amino acid residues are shown in white, while the carbon atoms of the DNA are shown in yellow. Ionic interactions and hydrogen bonds are represented as dashed lines. 
compounds could inhibit the isoform $\beta$, which justifies their higher cytotoxicity on Vero cells in comparison with the non-acetylated compounds. ${ }^{24}$ On the other hand, the expression of topoisomerase II $\alpha$ is increased in many cancer cells lines, and the inhibition of this isoform is related with the anticancer activity. ${ }^{45}$ Interestingly, only the most potent compounds 11e and 11c suggested to inhibit topoisomerase II $\alpha$ by intercalating with DNA complexed with the enzyme. Compound 11e showed stronger interactions with this enzyme in comparison with 11c. Also, 11e resembled the binding mode of a known inhibitor with the ATPase domain of topoisomerase II $\alpha$, which could contribute to its cytotoxic profile on cancer cells and explain its more significant activity and selectivity in comparison with the other compounds studied.

\section{Conclusions}

In summary, we synthesized sixteen new acetylated 1,2,3-triazoles-quinoidic derivatives (10a-10h and 11a-11h) in very good yields and screened it against Caco-2 cells and evaluated their cell viability on Vero cells. All derivatives were hemocompatible and the compound 11e exhibited the most promising profile against Caco- 2 cells due to its higher selectivity index, which was confirmed by in silico studies. Molecular docking showed that these compounds could exert their cytotoxic activity through inhibition of one topoisomerase II isoform, at least. Interestingly, the acetylation of these compounds seems to influence their interaction with different topoisomerases. For instance, a related naphthoquinone compound was suggested to inhibit only topoisomerase I and II $\alpha$, whereas the acetylated compounds studied herein could inhibit topoisomerase II $\alpha$ and II $\beta$, and probably do not inhibit topoisomerase I. Among the tested compounds, 11e had stronger interactions with the DNA-binding domain as well as the ATPase domain of topoisomerase II $\alpha$ which may explain its higher potency and selectivity. These results encourage new studies of molecular mechanism and the development of more potent and selective derivatives.

\section{Supplementary Information}

Supplementary data are available free of charge at http://jbcs.sbq.org.br as PDF file.

\section{Acknowledgments}

Fellowships granted by Conselho Nacional de Desenvolvimento Científico e Tecnológico (CNPq), CoordenaçãodeAperfeiçoamentodePessoal deNívelSuperior
(CAPES) and Fundação de Amparo à Pesquisa do Estado do Rio de Janeiro (FAPERJ) are gratefully acknowledged. This work was partially supported by FAPERJ grant numbers E-26/203.191/2017, E-26/010.101106/2018, E-26/202.800/2017, E-26/010.003002/2014; CNPq 301873/2019-4, 306011/2020-4 and CAPES Financial Code 001. Fundação Oswaldo Cruz (FIOCRUZ) was also acknowledged for HRMS analyses.

\section{Author Contributions}

Dora C. S. Costa was responsible for organic synthesis work and contributions to manuscript writing; Adriane S. Francisco for MTT assay on Caco-2 and Vero cells; Beatriz V. A. Matuck for organic synthesis work; Priscila S. Furtado for platelet aggregation and hemolysis tests; Alana A. S. C. de Oliveira for prothrombin time (PT) and activated partial thromboplastin time (aPTT) tests; Vitor WonHeld Rabelo for in silico studies; Plínio C. Sathler for execution and planning of hemocompatibility studies; Paula A. Abreu for in silico studies; Vitor F. Ferreira for coordination of organic synthesis work, contributions to manuscript writing; Luiz Cláudio R. P. da Silva for coordination of biological assays, contributions to manuscript writing; Fernando de C. da Silva for coordination of organic synthesis work, contributions to manuscript writing.

\section{References}

1. World Health Organization (WHO); Cancer, www.who.int/ news-room/fact-sheets/detail/cancer, accessed in July 2021.

2. Delgado, J. L.; Hsieh, C. M.; Chan, N. L.; Hiasa, H.; Biochem. J. 2018, 475, 373.

3. Hooper, D. C.; Jacoby, G. A.; Cold Spring Harbor Perspect. Med. 2016, 6, a025320.

4. Oblak, M.; Grdadolnik, S. G.; Kotnik, M.; Jerala, R.; Filipic, M.; Solmajer, T.; Bioorg. Med. Chem. Lett. 2005, 15, 5207.

5. Lübbers, T.; Angehrn, P.; Gmünder, H.; Herzig, S.; Kulhanek, J.; Bioorg. Med. Chem. Lett. 2000, 10, 821.

6. Kaur, M.; Mehta, V.; Wani, A. A.; Arora, S.; Bharatam, P. V.; Sharon, A.; Singh, S.; Kumar, R.; Bioorg. Chem. 2021, 114, 105114.

7. Boehm, H.-J.; Boehringer, M.; Bur, D.; Gmuender, H.; Huber, W.; Klaus, W.; Kostrewa, D.; Kuehne, H.; Luebbers, T.; Meunier-Keller, N.; Mueller, F.; J. Med. Chem. 2000, 43, 2664.

8. Brvar, M.; Perdih, A.; Hodnik, V.; Renko, M.; Anderluh, G.; Jerala, R.; Solmajer, T.; Bioorg. Med. Chem. 2012, 20, 2572.

9. Ronkin, S. M.; Badia, M.; Bellon, S.; Grillot, A.-L.; Gross, C. H.; Grossman, T. H.; Mania, N.; Parsons, J. D.; Stamos, D.; Trudeau, M.; Wei, Y.; Charifson, P. S.; Bioorg. Med. Chem. Lett. 2010, 20, 2828.

10. Trzoss, M.; Bensen, D. C.; Li, X.; Chen, Z.; Lam, T.; Zhang, J.; Creighton, C. J.; Cunningham, M. L.; Kwan, B.; Stidham, 
M.; Nelson, K.; Brown-Driver, V.; Castellano, A.; Shaw, K. J.; Lightstone, F. C.; Wong, S. E.; Nguyen, T. B.; Finn, J.; Tari, L. W.; Bioorg. Med. Chem. Lett. 2013, 23, 1537.

11. Sherer, B. A.; Hull, K.; Green, O.; Basarab, G.; Hauck, S.; Hill, P.; Loch $3^{\text {rd }}$ J. T.; Mullen, G.; Bist, S.; Bryant, J.; Boriack-Sjodin, A.; Read, J.; DeGrace, N.; Uria-Nickelsen, M.; Illingworth, R. N.; Eakin, A. E.; Bioorg. Med. Chem. Lett. 2011, 21, 7416.

12. Kumar, B. S.; Ravi, K.; Verma, A. K.; Fatima, K.; Hasanain, M.; Singh, A.; Sarkar, J.; Luqman, S.; Chanda, D.; Negi, A. S.; Bioorg. Med. Chem. 2017, 25, 1364.

13. Ferreira, S. B.; Gonzaga, D. T. G.; Santos, W. C.; Araújo, K. G. L.; Ferreira, V. F.; Rev. Virtual Quim. 2010, 2, 140.

14. Wellington, K. W.; RSC Adv. 2015, 5, 20309.

15. Ferreira, F. R.; Ferreira, S. B.; Araújo, A. J.; Filho, J. D. B. M.; Pessoa, C.; Moraes, M. O.; Costa-Lotufo, L. V.; Montenegro, R. C.; da Silva, F. C.; Ferreira, V. F.; da Costa, J. G.; de Abreu, F. C.; Goulart, M. O. F.; Electrochim. Acta 2013, 110, 634.

16. Cardoso, M. F. C.; da Silva, I. M. C. B.; dos Santos Jr., H. M.; Rocha, D. R.; Araújo, A. J.; Pessoa, C.; de Moraes, M. O.; Lotufo, L. V. C.; da Silva, F. C.; Santos, W. C.; Ferreira, V. F.; J. Braz. Chem. Soc. 2013, 24, 12.

17. Cardoso, M. F.; Rodrigues, P. C.; Oliveira, M. E.; Gama, I. L.; da Silva, I. M. C. B.; Santos, I. O.; Rocha, D. R.; Pinho, R. T.; Ferreira, V. F.; de Souza, M. C. B. V.; da Silva, F. C.; Silva Jr., F. P.; Eur. J. Med. Chem. 2014, 84, 708.

18. Inagaki, R.; Ninomiya, M.; Tanaka, K.; Koketsu, M.; ChemMedChem 2015, 10, 1413.

19. Chipoline, I. C.; Alves, E.; Branco, P.; Costa-Lotufo, L. V.; Ferreira, V. F.; da Silva, F. C.; An. Acad. Bras. Cienc. 2018, 90, 1027

20. Gerber, D. E.; Beg, M. S.; Fattah, F.; Frankel, A. E.; Fatunde, O.; Arriaga, Y.; Dowell, J. E.; Bisen, A.; Leff, R. D.; Meek, C. C.; Putnam, W. C.; Kallem, R. R.; Subramaniyan, I.; Dong, Y.; Bolluyt, J.; Sarode, V.; Luo, X.; Xie, Y.; Schwartz, B.; Boothman, D. A.; Br. J. Cancer 2018, 119, 928.

21. Shafei, A.; El-Bakly, W.; Sobhy, A.; Wagdy, O.; Reda, A.; Aboelenin, O.; Marzouk, A.; Habak, K. E.; Mostafa, R.; Ali, M. A.; Ellithy, M.; Biomed. Pharmacother. 2017, 95, 1209.

22. Ma, X.; Huang, X.; Moore, Z.; Huang, G.; Kilgore, J. A.; Wang, Y.; Hammer, S.; Williams, N. S.; Boothman, D. A.; Gao, J.; J. Controlled Release 2015, 200, 201.

23. Reichstein, A.; Vortherms, S.; Bannwitz, S.; Tentrop, J.; Prinz, H.; Muller, K.; J. Med. Chem. 2012, 55, 7273.

24. Costa, D. C. S.; de Almeida, G. S.; Rabelo, V. W.; Cabral, L. M.; Sathler, P. C.; Abreu, P. A.; Ferreira, V. F.; da Silva, L. C. R. P.; da Silva, F. C.; Eur. J. Med. Chem. 2018, 156, 524.

25. Mosmann, T.; J. Immunol. Methods 1983, 65, 55.

26. Alley, M. C.; Scudiero, D. A.; Monks, A.; Hursey, M. L.; Czerwinski, M. J.; Fine, D. L.; Abbott, B. J.; Mayo, J. G.; Shoemaker, R. H.; Boyd, M. R.; Cancer Res. 1988, 48, 589.
27. GraphPad Prism, version 5.00; GraphPad Software, Inc.; USA, 2008.

28. Sathler, P. C.; Lourenço, A. L.; Rodrigues, C. R.; da Silva, L. C. R. P.; Cabral, L. M.; Jordão, A. L.; Cunha, A. C.; de Souza, M. C. B. V.; Ferreira, V. F.; Carvalho-Pinto, C. E.; Kang, H. C.; Castro, H. C.; Thromb. Res. 2014, 134, 376.

29. Parnham, M. J.; Wetzig, H.; Chem. Phys. Lipids 1993, 64, 263.

30. Fischer, D.; Li, Y.; Ahlemeyer, B.; Krieglstein, J.; Kissel, T.; Biomaterials 2003, 24, 1121.

31. Bauer, M.; Lautenschlaeger, C.; Kempe, K.; Tauhardt, L.; Schubert, U. S.; Fischer, D.; Macromol. Biosci. 2012, 12, 986.

32. Martinichen-Herrero, J. C.; Carbonero, E. R.; Sassaki, G. L.; Gorin, P. A.; Iacomini, M.; Int. J. Biol. Macromol. 2005, 35, 97.

33. Fonseca, R. J.; Sucupira, I. D.; Oliveira, S. N.; Santos, G. R.; Mourão, P. A.; Thromb. Haemostasis 2017, 117, 662.

34. Staker, B. L.; Hjerrild, K.; Feese, M. D.; Behnke, C. A.; Burgin Jr., A. B.; Stewart, L.; Proc. Natl. Acad. Sci. U. S. A. 2002, 99, 15387.

35. Wang, Y. R.; Chen, S. F.; Wu, C. C.; Liao, Y. W.; Lin, T. S.; Liu, K. T.; Chen, Y. S.; Li, T. K.; Chien, T. C.; Chan, N. L.; Nucleic Acids Res. 2017, 45, 10861.

36. Wu, C. C.; Li, T. K.; Farh, L.; Lin, L. Y.; Lin, T. S.; Yu, Y. J.; Yen, T. J.; Chiang, C. W.; Chan, N. L.; Science 2011, 333, 459.

37. Wei, H.; Ruthenburg, A. J.; Bechis, S. K.; Verdine, G. L.; J. Biol. Chem. 2005, 280, 37041.

38. Spartan, version 10; Wavefunction, Inc., Japan Branch Office, Japan, 2011.

39. Autodock Tools, version 1.5.7; Molecular Graphics Laboratory, The Scripps Research Institute, USA, 2010.

40. Autodock Vina, version 1.1.2; Molecular Graphics Laboratory, The Scripps Research Institute, USA, 2011; Trott, O.; Olson, A. J.; J. Comput. Chem. 2010, 31, 455.

41. The PyMOL Molecular Graphics System, Pymol, version 1.2r2; Schrödinger, LLC, 2018.

42. SigmaPlot, version 12.5; Systat Software Inc., Cranes Software International Limited, USA/Canada, 2013.

43. da Silva, I. F.; Martins, P. R.; da Silva, E. G.; Ferreira, S. B.; Ferreira, V. F.; da Costa, K. R.; de Vasconcellos, M. C.; Lima, E. S.; da Silva, F. C.; Med. Chem. 2013, 9, 1085.

44. ISO 10993-5:2009: Biological Evaluation of Medical Devices Part 5: Tests for in Vitro Cytotoxicity, International Organization for Standardization (ISO): Geneva, 2009, p. 24.

45. Wu, C. C.; Li, Y. C.; Wang, Y. R.; Li, T. K.; Chan, N. L.; Nucleic Acids Res. 2013, 41, 10630.

46. Pommier, Y.; ACS Chem. Biol. 2013, 8, 82.

Submitted: July 13, 2021

Published online: August 31, 2021 